\title{
Indirect Assessment of Sedimentation in Hydropower Dams Using MODIS Remote Sensing Images
}

\author{
Rita de Cássia Condé ${ }^{1,2, *}$, Jean-Michel Martinez ${ }^{2,3, *}$, , Marco Aurélio Pessotto ${ }^{4}$, Raúl Villar ${ }^{5}$ (D), \\ Gérard Cochonneau ${ }^{3}{ }^{\circ}$, Raoul Henry ${ }^{4}$, Walszon Lopes ${ }^{1}$ and Marcos Nogueira ${ }^{4}$ \\ 1 Agência Nacional de Águas (ANA), Setor Policial, Área 5, Qd. 3, Bloco L, Brasília CEP 70610-200, Brazil; \\ walszon@ana.gov.br \\ 2 Instituto de Geociências, Universidade de Brasília (UnB), Campus Universitário Darcy Ribeiro, ICC Centro, \\ Brasília CEP 70.910-900, Brazil \\ 3 Géosciences Environnement Toulouse (GET), UMR5563, Institut de Recherche pour le \\ Développement (IRD)/Centre National de la Recherche Scientifique (CNRS)/Université Toulouse 3, \\ 14 Avenue Edouard Belin, 31400 Toulouse, France; gerard.cochonneau@ird.fr \\ 4 Departamento de Zoologia, Instituto de Biociências, Universidade Estadual Paulista (UNESP), \\ Distrito de Rubião Júnior, Botucatu CEP 18618-970, Brazil; marcoaurelio.pessotto@gmail.com (M.A.P); \\ rhenry@ibb.unesp.br (R.H); marcos.nogueira@unesp.br (M.N) \\ 5 Instituto Geofísico del Perú (IGP), Calle Badajoz 169, Urb. Mayorazgo IV etapa, Ate, Lima 15012, Peru; \\ raul_ev@hotmail.com \\ * Correspondence: ritacondebrasil@hotmail.com (R.d.C.C.); martinez@ird.fr (J.-M.M.); \\ Tel.: +55-61-98619-0193 (R.d.C.C.); +55-61-9999-1974 (J.-M.M.)
}

Received: 27 December 2018; Accepted: 31 January 2019; Published: 5 February 2019

\begin{abstract}
In this study, we used moderate resolution imaging spectroradiometer (MODIS) satellite images to quantify the sedimentation processes in a cascade of six hydropower dams along a 700-km transect in the Paranapanema River in Brazil. Turbidity field measurement acquired over 10 years were used to calibrate a turbidity retrieval algorithm based on MODIS surface reflectance products. An independent field dataset was used to validate the remote sensing estimates showing fine accuracy (RMSE of 9.5 NTU, $r=0.75, \mathrm{~N}=138$ ). By processing 13 years of MODIS images since 2000, we showed that satellite data can provide robust turbidity monitoring over the entire transect and can identify extreme sediment discharge events occurring on daily to annual scales. We retrieved the decrease in the water turbidity as a function of distance within each reservoir that is related to sedimentation processes. The remote sensing-retrieved turbidity decrease within the reservoirs ranged from 2 to $62 \%$ making possible to infer the reservoir type and operation (storage versus run-of-river reservoirs). The reduction in turbidity assessed from space presented a good relationship with conventional sediment trapping efficiency calculations, demonstrating the potential use of this technology for monitoring the intensity of sedimentation processes within reservoirs and at large scale.
\end{abstract}

Keywords: Paranapanema River; turbidity; sedimentation; remote sensing; sediment trap efficiency; reservoir; river sediment discharge; suspended particulate matter; MODIS; water color

\section{Introduction}

The construction of large reservoirs worldwide represents a primary modification to fluvial sediment transport processes induced by anthropogenic activities. Dams and reservoirs modify the fluvial sediment transport capacity, which in turn affects the river geomorphology [1], water geochemical composition [2] and ecology [3]. There are approximately 50,000 large dams higher than $15 \mathrm{~m} \mathrm{[4]}$, with the number increasing significantly in the latter half of the 20th century. It is estimated 


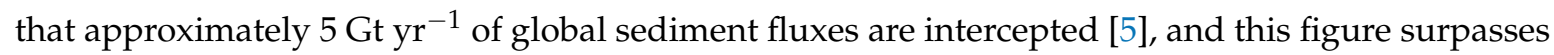
the net increase in sediment delivery induced by land use changes [6].

Because of the environmental concerns cited above, large dams stopped being built in developed countries and more dams are currently being removed in North America and Europe than are being built [7]. However, the growing need for renewable energy makes necessary to improve the management of existing large dams in order to extend their lifespan and maintain the hydropower contribution to the global electricity production [8]. Understanding and management of sediment is no less important than hydraulic control if reservoirs are to provide sustainable, long-term service at acceptable levels of environmental impact [9]. Accumulation of sediment in the dam impoundment (e.g., sedimentation) is considered as the major and most common threat to existing infrastructure by reducing the water retention capacity. Consequently, the monitoring of sedimentation in hydropower dams is considered as a priority and innovative solutions must be evaluated to improve the management of existing reservoirs, particularly those used for hydropower [10]. Conventional methods for assessment of sediment trap efficiency measurement include sediment load balance at different point along the river system for computing mid to short-term variations in sediment yield or repeated bathymetric surveys to calculate the sediment volumes stored at the lake bottom. Both solutions are extremely time consuming and costly and the protocols used are inhomogeneous.

Dams and reservoirs are used for multiple purposes, including water resource control, irrigation and electricity generation. Although hydroelectricity may represent nearly $25 \%$ of the world's electric power generation, this rate increased to $97 \%$ during the 1990s in Brazil [11]. In this country, the option for a hydroelectric matrix was strongly influenced by the presence of large fluvial systems, such as the Amazon River (north), Paraná River (southeast) and São Francisco River (northeast). The Paraná basin has the largest hydroelectric potential in operation in South America and there are more than 150 large reservoirs for power generation in the Paraná River and its main tributaries (Grande, Paranaiba, Tiête, Paranapanema and Iguaçu rivers) [12].

Understanding sediment transportation within catchments is required for water resource management and represents an important environmental index for monitoring the impact of anthropogenic activities. Various socioeconomic activities based on the use of surface waters require information on the suspended sediment quantity and quality. Assessments of the rate of reservoir sedimentation are crucial for calculating a dam's life expectancy and for optimizing dam operations, whether for purposes of irrigation, hydroelectricity or flood control. The transport of nutrients and contaminants, such as heavy metals, is known to be driven by suspended sediment fluxes, and these constituents may eventually be stored in impoundments. However, modifying sediment fluxes through impounding complicates the analysis of river system responses to global and regional changes [13].

The Brazilian Water Agency (ANA) manages 500 sediment stations that are distributed throughout the country and are used to determine the suspended particulate matter (SPM) on a quarterly basis. Considering the national land size and the importance of water resources for environmental and economic purposes, the network's spatial coverage and SPM sampling frequency should be considered insufficient. Although improving the monitoring capacity would increase the operational cost of the federal hydrological network significantly, such improvements are crucial. Therefore, alternative techniques may be evaluated for completing and extending the current monitoring capacities based on conventional monitoring methods that utilize field measurements.

Optical remote sensing can be efficiently used for monitoring water color or the spectral behavior of water. Water color is linked to the presence of optically active components within the water column, and three main components alter the optical properties of water in the visible and infrared wavelength ranges [14]: colored dissolved organic matter (CDOM), SPM (either organic or inorganic) and photosynthetic pigments, such as chlorophyll-a (Chl-a). Light absorption and scattering by water presents a limited dependency on temperature and salinity. The presence and concentration of each optically active component controls the light absorption and scattering processes. Consequently, 
analyses of the upwelling light emerging from a water body makes possible to infer some water quality parameters such as SPM or chlorophyll-a.

Significant knowledge has been obtained on the optical properties of oceanic and continental waters through experimental measurements, modeling approaches and remote sensing methods. Numerous studies have indicated that the red and infrared wavelengths are appropriate for retrieving SPM concentrations; however, the optical properties/SPM relationships may depend on the nature of the concentration range, water type and particulate matter content [15-18]. Unfortunately, the complex interactions between optically active components have complicated the development of universal retrieval algorithms [14]. Thus, conventional approaches adopted by several studies rely on the calibration of a retrieval algorithm according to site-specific data [19-26]. [27,28] compared empirical models for turbid coastal and inland waters published in 31 and 25 articles, respectively, showing that the reflectance/SPM or reflectance/turbidity models display a large variety in terms of mathematical expression, spectral bands used and the turbidity/SPM concentration range. However, [16] demonstrated that the optical properties of the main Amazonian rivers are stable enough to support operational SPM monitoring using satellite data; thus, a unique retrieval algorithm may be used regardless of the river and hydrological period considered within a large catchment. This promising result, which was achieved in the world's largest watershed, must be confirmed for other catchments to determine whether it is dependent on the watershed water optical properties and whether specific retrieval algorithms need to be developed for each watershed or derived at different scales according to the variability of vegetation, soils and geomorphological characteristics.

The use of satellite data for water quality monitoring over open water bodies may be hampered by the spatial, temporal and spectral resolution of the images, which can limit the retrieval capacity of the sensor [29]. Therefore, selecting the correct spaceborne platform is critical and depends on the application. In the case of hydro-sedimentary studies, fine temporal resolution monitoring is mandatory because the sediment fluxes vary considerably over time. Thus, spaceborne platforms offering fine revisiting frequency together with fine radiometric calibration and sufficient spectral resolution should be prioritized.

In recent years, studies have demonstrated that satellite data offering daily global coverage, such as that obtained by moderate resolution imaging spectroradiometer (MODIS) sensors, are appropriate for monitoring SPM concentrations in large rivers, such as the Amazon basin [24,26,30-34]. In particular, MODIS is capable of monitoring surface SPM over more than 10 years at different river gauges (1-km wide or larger) and at intermediate to high levels of SPM concentration (10 to $1000 \mathrm{mg} \mathrm{L}^{-1}$ ) [35]. However, assessing MODIS data for smaller catchments and lower levels of turbidity remains a challenge, and whether these data can efficiently monitor sedimentary patterns in reservoirs and lakes is unclear.

The objective of this work is to evaluate the use of MODIS remote sensing data for the synoptic monitoring of sedimentation in a series of hydroelectric dams in southern Brazil. Sedimentation occurs as a function of suspended sediment deposition in reservoir because of flow velocity decrease from a riverine flow to a lake flow. Consequently, there is an inverse (indirect) relationship between water turbidity and the intensity of the sedimentation processes. We aim to demonstrate that satellite data, through the monitoring of spatial and seasonal turbidity variation in reservoirs, provide consistent estimates of sedimentation in reservoirs. To this end, a 13-year time series of satellite data was processed to calculate turbidity at different points over six different reservoirs. A reflectance retrieval model is calibrated and validated using two independent field turbidity data sets acquired in the catchment. The remote sensing derived turbidity time series retrieved are analyzed as a function of reservoirs' operational characteristics and flow conditions. In particular, we compare the satellite-derived turbidity decrease with the prediction of a sediment trap efficiency model. A methodology based on remote sensing for indirect assessment of sedimentation processes in reservoirs is then proposed. 


\section{Materials and Methods}

\subsection{Paranapanema River Catchment}

The Paranapanema River is an important tributary along the left bank of the Paraná River, and it flows from central Brazil southward to Argentina and Uruguay (La Plata Basin). The Paranapanema River is $930 \mathrm{~km}$ long, and its catchment area is $100,800 \mathrm{~km}^{2}$. The mean basin declivity is $61 \mathrm{~cm} / \mathrm{km}$ and further upstream, there is a declivity of $150 \mathrm{~cm} / \mathrm{km}$ in the first 100-km river stretch [36,37].

The precipitation rate decreases and temperature increases from upstream to downstream. Upstream, the mean annual precipitation varies between $1500-1700 \mathrm{~mm}$ and the mean annual temperature is lower than $19{ }^{\circ} \mathrm{C}$, whereas downstream, the mean annual precipitation falls to $1100-1300 \mathrm{~mm}$ and the mean annual temperature is higher than $23^{\circ} \mathrm{C}$. Seasonally, precipitation exhibits a marked dry period of up to three months, and it usually occurs between July and September (winter to early spring), with an intensive rainfall period in summer (December to March).

The Paranapanema catchment has been subjected to intense deforestation for cattle raising and agriculture, and the native vegetation is now restricted to preserved isolated fragments and restoration initiatives. Land cover changes and intense farming (e.g., intensive sugar-cane plantations) have contributed to soil degradation and consequently, increased erosion and fluvial sediment transportation [38,39].

Over the last six decades, the main course of the river has been intensively dammed for hydropower production, and eleven reservoirs were constructed with distinct sizes, operational designs and limnological/water quality characteristics [37,40]. Various studies have assessed the impact of the dam cascade, especially the effects of multiple reservoirs on the limnological functioning of the river system and spatial compartmentalization [37,40,41]. Pronounced impoundment effects along the cascade, especially in the larger reservoirs, were demonstrated. In addition to conspicuous changes in channel morphometry, flow and water level regime, other important modifications include a longitudinal increase in temperature, the development of seasonal thermal stratification in deeper zones next to the dams and associated phenomena, such as oxygen depletion in the bottom layers, increased transparency in the water column, and nutrient and organic matter accumulation in the sediments. The biotic communities also exhibited conspicuous modifications because of the river damming, including an increase in the plankton biomass [42,43], which can influence the optical responses of the water.

\subsection{Characteristics of the Hydropower Dams}

The Paraná River catchment produces $60 \%$ of the country's hydropower (38,916 MW) and accounts for $75 \%$ of the national consumption [44]. The Brazilian segment of the Paraná River catchment hosts $32 \%$ of the country's population, and there are 179 hydroelectric power plants installed in Brazil, of which eleven are found within the Paranapanema catchment, and their output totals 2432 MW [44]. Figure 1 shows the locations of the reservoirs in the Paranapanema catchment, and Table 1 lists the main characteristics of the six hydropower dams selected for the study. The reservoirs are conveniently labeled from I to VI, starting from the upstream reservoirs.

The reservoirs exhibit major differences in relation to size, water storage and residence time. The largest (storage) reservoirs are \#I (Jurumirim), \#II (Chavantes) and \#IV (Capivara), which represent the primary sources of modifications to the natural water flow because they are operated for hydroelectricity and flow control. The other impoundments are run-of-river reservoirs, meaning that they have a limited amount of water storage, representing a few hours or few days of river water inflow. These run-of-river reservoirs are primarily used for hydroelectricity, including reservoirs \#III (Canoas II) and \#V (Taquaraçu). The mean water residence time varies considerably from 7 days (reservoir \#III) to 340 days (reservoir \#I). 


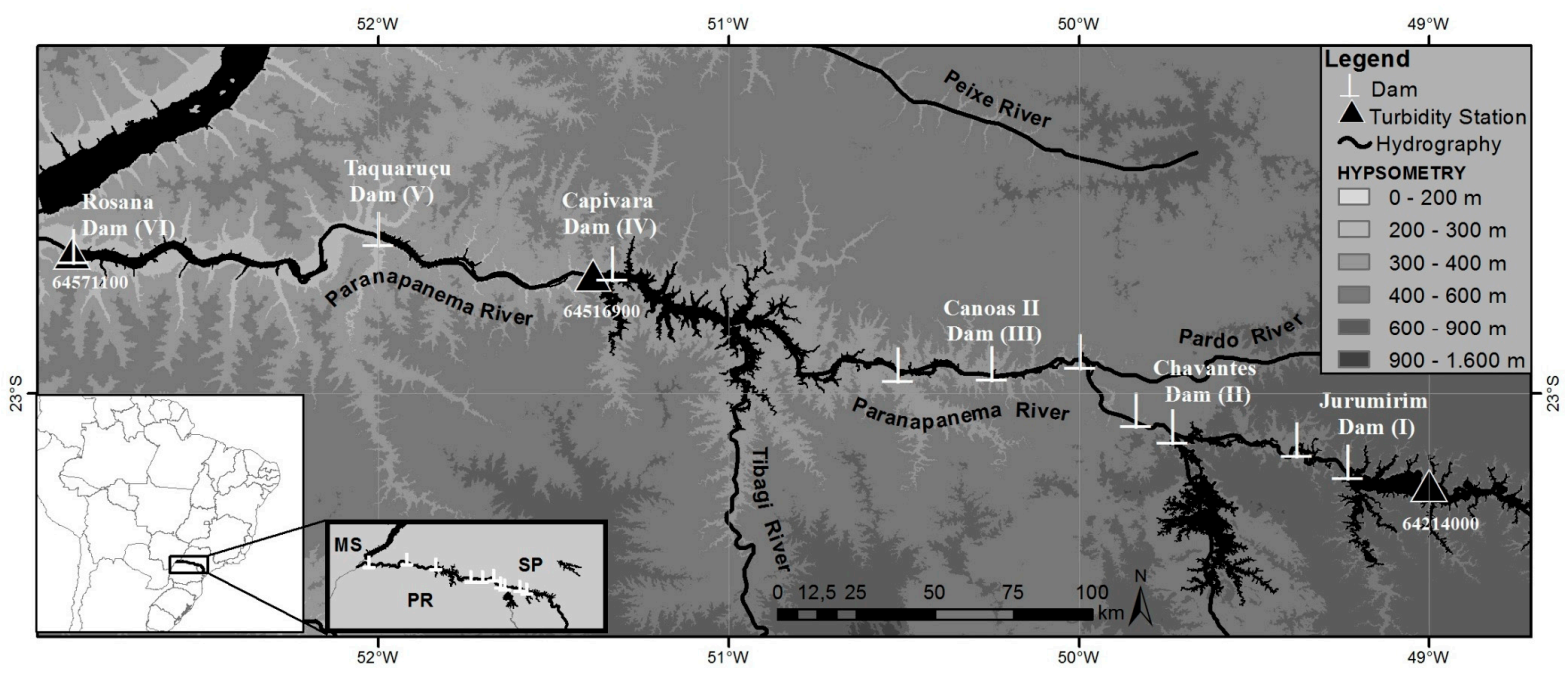

Figure 1. Map of the Paranapanema River catchment showing the locations of the hydropower dams (white bars) and turbidity sampling stations (black triangles). The six reservoirs studied in this article are numbered from upstream to downstream (I to VI).

Table 1. Characteristics of the six studied hydropower dams distributed along the Paranapanema River.

\begin{tabular}{|c|c|c|c|c|c|}
\hline Reservoirs & $\begin{array}{l}\text { Open Water } \\
\text { Mean Area } \\
\left(\mathbf{k m}^{2}\right)^{1}\end{array}$ & $\begin{array}{c}\text { Drainage Area } \\
\left(\mathrm{km}^{2}\right)^{2}\end{array}$ & $\begin{array}{c}\text { Mean Water } \\
\text { Residence Time } \\
\text { (days) }^{3}\end{array}$ & $\begin{array}{l}\text { Mean Reservoir } \\
\text { Depth }(\mathrm{m})^{3}\end{array}$ & $\begin{array}{l}\text { Mean Output } \\
\text { Flow }\left(\mathrm{m}^{3} \mathrm{~s}^{-1}\right)^{3}\end{array}$ \\
\hline I-Jurumirim & 449 & 17,891 & 340 & 14.7 & 236 \\
\hline II-Chavantes & 400 & 27,769 & 312 & 21.2 & 324 \\
\hline III-Canoas II & 23 & 39,531 & 7 & 6.0 & 477 \\
\hline IV-Capivara & 576 & 84,715 & 111 & 17.6 & 1091 \\
\hline V-Taquaruçu & 80 & 88,707 & 8 & 8.9 & 1137 \\
\hline VI-Rosana & 220 & 100,799 & 17 & 8.7 & 1289 \\
\hline
\end{tabular}

Sources: ${ }^{1}$ http://www.duke-energy.com.br/usinas/Paginas/Usinas.aspx; ${ }^{2}$ Brazilian Water Agency, 2007; ${ }^{3}$

Calculated from the data provided by the Duke Energy Company and the Brazilian Water Agency.

\subsection{Water Quality Database}

Two independent turbidity datasets were used for the calibration and validation of remote sensing-derived estimates. For calibration, turbidity records were provided by Companhia Ambiental do Estado de São Paulo (CETESB), the regional public company in charge of water, air and soil monitoring and quality control. Data were available for 3 stations (Jusante Rosana-6457.1100, Jusante Capivara-6451.6900 and Jurumirim Reserva-64214000) (Figure 1) located within reservoirs \#I and \#V and downstream of reservoir \#VI. Water was sampled every two months using 250-ml sampling bottles. Turbidity was measured in a laboratory following the method outlined in the Standard Methods 2130-B [45] using a Hach turbidimeter. The turbidimeter makes the determination using a primary nephelometric light scatter signal, 90 degrees to the transmitted light scatter signal. This method is based on a comparison between the intensity of light scattered by the sample and the intensity of light scattered by a standard reference solution. The turbidity records cover the period from 2000 to 2010, and a total of 188 samples were obtained from the three stations.

For validation, we used 138 turbidity measurements collected at 37 sampling stations during 14 field sampling trips conducted in October 2013; February and March 2014; February, March, April, June, July, October and November 2015; and February, March, June and July 2016 [40]. The sampling stations were located across the Paranapanema River reservoirs, and measurements were conducted using a multiparameter water quality meter (Horiba U-52, Japan). The U-52 sensor uses a pulse light LED (infra-red emitting diode) as a light source, and detect scattered light from a 30 degree angle off center. Although both turbidimeters used for calibration and validation deliver turbidity estimates in 
NTU units, it is important to note that the measurement protocols of each instrument are different in terms of reference scattering angle and of light source. These differences may introduce a bias in the validation results [46].

\subsection{Processing of Remote Sensing Images}

MODIS remote sensing images acquired from the Aqua and Terra satellites were used in this study. The MODIS data product MOD09Q1/MYD09Q1 provides calibrated reflectance for two bands measured at a resolution of $250 \mathrm{~m}$ (http:/ / modis.gsfc.nasa.gov) by the sensors onboard the Terra and Aqua satellites. Band 1 is centered at $645 \mathrm{~nm}$, and Band 2 is centered at $858.5 \mathrm{~nm}$. The MODIS 250- and 500-m bands were originally designed for land studies and cloud detection and therefore have lower sensitivities than the MODIS ocean bands. However, through comparison with other sensors including Landsat-7 ETM+, CZCS, and SeaWiFS, [21] determined that these bands do provide sufficient sensitivity for water applications.

MODIS surface reflectance eight-day composite data in HDF format were acquired between February 2000 and November 2012 from the NASA Earth Observing System (EOS) data gateway. MODIS sensors offer near-daily coverage over tropical areas, although the cloud coverage limits the availability of satellite images, especially during the rainy season. Eight-day image composites were considered for this study because they reduce the amount of data to be analyzed, as a large number of daily images cannot be used because of the persistent cloud cover; in addition they significantly reduce the bidirectional reflectance distribution function effects and atmospheric artifacts [29]. The composites from the Terra and Aqua satellite time series were processed independently and were merged to produce a unique time series. For each date, the Terra and Aqua eight-day composites were compared, and the image with the lowest averaged satellite viewing angle was selected. If both composites had the same viewing angle, the composite with the lowest cloud coverage was selected. For this work, 585 and 489 MODIS eight-day composites were processed for the Terra (available since February 2000) and Aqua (available since July 2002) data, respectively.

The coarse spatial resolution of MODIS data may result in mixed pixels in which both open water and lake/river banks appear. This phenomenon causes spectral mixing in which the pixel spectral signature is a mixture of distinct target spectra. Because the effective satellite resolution varies from one image to another as a function of the zenith viewing angle, mixed pixel localization may vary from one image to another. Furthermore, the open water area varies as a function of the hydrology. To overcome this variability and automatically process the image time series, we used the MOD3R (MODIS Reflectance Retrieval over Rivers) program, which we developed from previous investigations $[31,32,35,47]$. The MOD3R program can be used to identify unmixed water pixels automatically over a virtual station without any additional information. The program classifies the virtual station pixels in homogeneous clusters using an unsupervised K-means algorithm. Linear mixing models (LMMs) are iteratively tested to identify the water endmembers.

For each reservoir, virtual stations were created within the water body and below the dam. The virtual station represents an area over which MODIS pixels are averaged to assess a representative reflectance of the zone and to limit the impact of cloud coverage. The size of the virtual station may vary according the objective of the analysis. For a synthetic view of each reservoir, a virtual station was created near the dam with a size varying between 12 pixels and 110 pixels for the largest reservoirs. Figures S1-S6 show the upstream and downstream virtual station positions for the six studied dams. For the analysis of intra reservoir variability, different virtual stations were created from upstream to downstream. Figure S7 shows the different virtual stations created along reservoir \#I to analyze the sedimentation pattern, where each station covers 350 to 450 pixels.

\subsection{Assessment of Reservoir Sedimentation}

Sedimentation in reservoirs is usually predicted with trap efficiency (TE) models that represent the amount (percentage) of the sediment delivered to a reservoir that remains in it [48]. Several empirical 
methods exist in the literature, the two most common approaches being the one initiated by Brune [49] and the other by Churchill [50]. The Brune method [49], which is based on the reservoir capacity and water inflow, is by far the most popular method, as it requires little input data. The Churchill method [50] requires additional data on the water inflow velocity, which is much more difficult to acquire on a daily basis. The Brune data [49] have been analyzed by several authors that proposed different empirical equations as reported by Heinemann [51] and for different suspended sediment size classes (e.g., coarse, medium and fine). Fine suspended sediment is of specific interest for our work because classical results of sediment transport dynamics in a turbulent flow system [52] predict an almost pure fine sediment composition at the river surface. Consequently, the surface reflectance that originates from the water column upper layer is controlled by the finest sediment class that is mostly related to clay particles. For this work, we used the equations derived by Gill [53] from Brune data for fine suspended sediment (e.g., clay) which proposed a trap efficiency model $\mathrm{TE}_{F S}$ :

$$
\mathrm{TE}_{F S}=100 \times\left(\frac{\tau^{3}}{1.02655 \tau^{3}+0.02621 \tau^{2}-0.133 \cdot 10^{-3} \tau+0.1 \cdot 10^{-5}}\right)
$$

where $\tau=V / Q$ is the water residence time in a reservoir (in years), $V$ is the reservoir volume $\left(\mathrm{m}^{3}\right)$ and $\mathrm{Q}$ is the mean annual inflow $\left(\mathrm{m}^{3} \cdot \mathrm{yr}^{-1}\right)$. The data to calculate Equation (1) were obtained from the Duke Energy Company, which provided both daily flow and reservoir volume data for each reservoir over the period considered in this work. We assumed the outflow discharge was equivalent to the inflow [54] rather than assessing the tributaries discharge to the reservoirs as many local streams are ungauged. In addition to the data calculated by the conventional methodology presented above, sedimentation analysis was performed using remote sensing-derived turbidity data. We assumed that the turbidity decrease in a reservoir is a proxy of the sedimentation process and we proposed an index to quantify the sedimentation and compare it with $\mathrm{TE}_{\mathrm{FS}}$. The remote sensing-derived turbidity decrease $\left(\mathrm{TD}_{\mathrm{RS}}\right)$ was calculated for each reservoir as:

$$
\mathrm{TD}_{R S}=100 \times\left(\frac{\sum_{i=1}^{n} T D_{i}^{u p}-\sum_{i=1}^{n} T D_{i}^{d a m}}{\sum_{i=1}^{n} T D_{i}^{u p}}\right)
$$

where $T D_{i}^{u p}$ is the satellite derived turbidity calculated for the most upstream virtual station on month $\mathrm{i}$ and $T D_{i}^{d a m}$ is the satellite derived turbidity calculated for the virtual station nearest to the dam on month i. Figures S1-S6 show, for each reservoir, the location of the virtual stations used to calculate Equation (2). Following the Equation (1) proposed by Gill [53], we defined a trap efficiency $\mathrm{TE}_{\mathrm{RS}}$ that relies only on remote sensing data using the $\mathrm{TD}_{\mathrm{RS}}$ index:

$$
\mathrm{TE}_{R S}=100 \times\left(\frac{\mathrm{TD}_{R S^{3}}}{a \cdot \mathrm{TD}_{R S}{ }^{3}+b \cdot \mathrm{TD}_{R S^{2}}+c \cdot \mathrm{TD}_{R S}+d}\right)
$$

We applied the different equations for each year and we analyzed the annual results from 2001 to 2012 as well as the overall result averaged over the period. We assessed the parameters a, b, c and d from Equation (3) by minimizing the difference between the annual estimates for $\mathrm{TE}_{\mathrm{RS}}$ and $\mathrm{TE}_{\mathrm{FS}}$ using generalized reduced gradient nonlinear algorithm from Excel Solver [55].

\section{Results}

\subsection{Surface Reflectance Temporal Behavior}

Figure 2 compares variations of the MODIS red-band surface reflectance with the daily outflow of each reservoir for the period 2000-2012. The surface reflectance is presented with a monthly time step. Table 2 summarizes the reflectance and water discharge time series statistics during the same period. Although the river water discharge is now largely controlled by the dam cascade, most of 
the higher reflectance peaks are associated with the flow discharge peaks, which promote increased water turbidity.

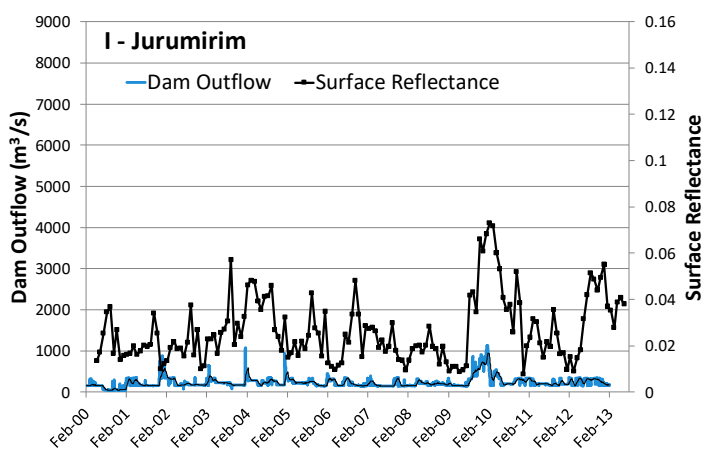

(a)

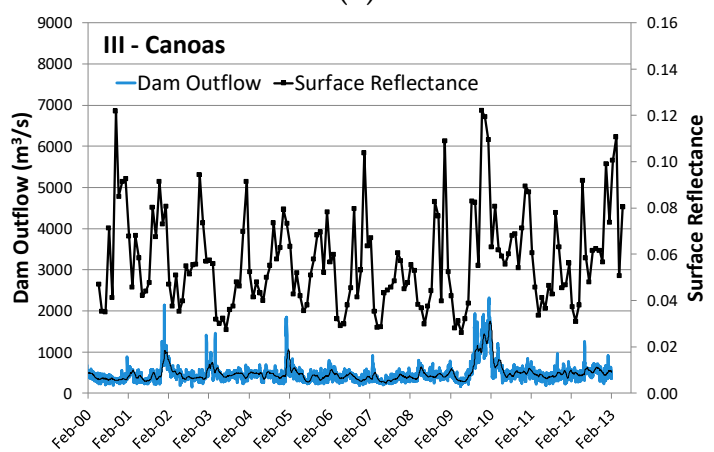

(c)

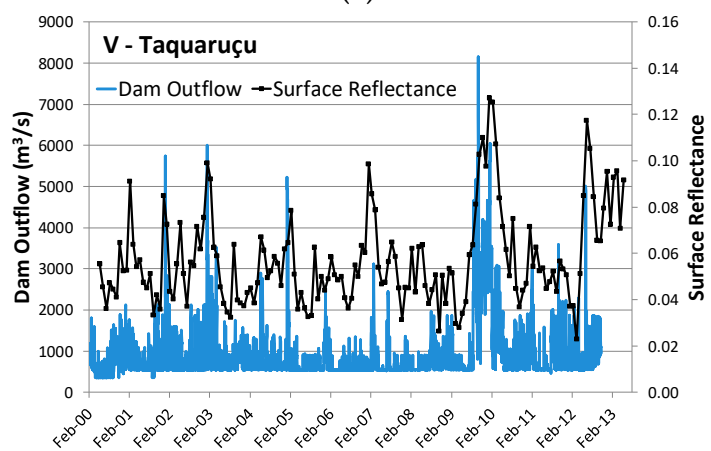

(e)

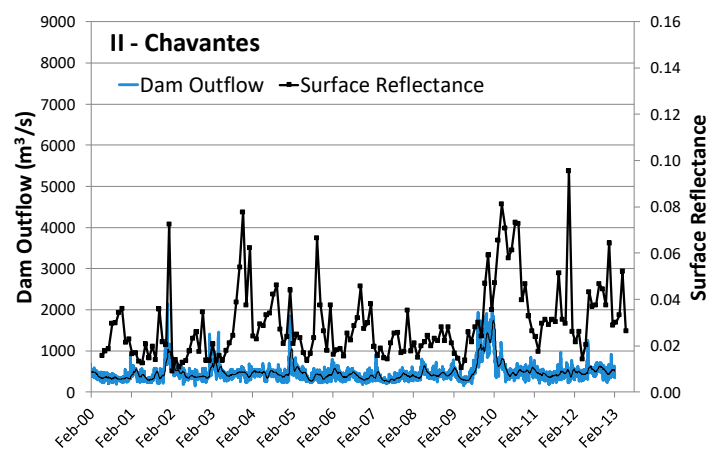

(b)

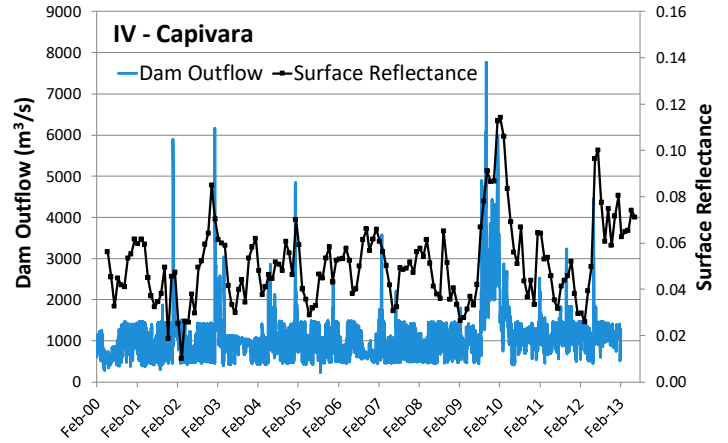

(d)

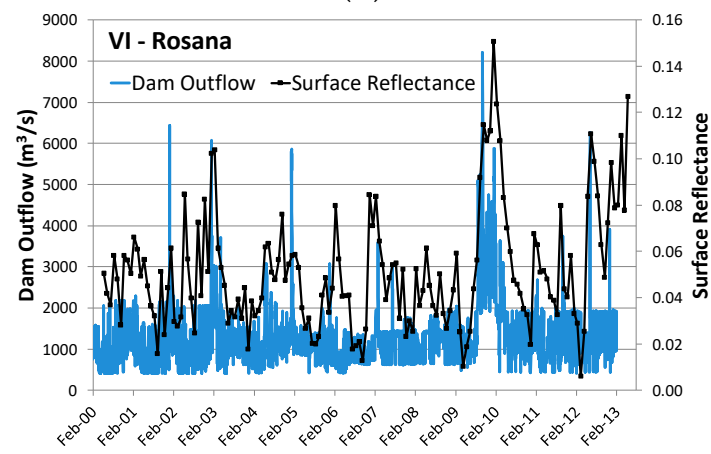

(f)

Figure 2. Daily dam water discharge and MODIS eight-day surface reflectance in red wavelengths retrieved from 2000 to 2013 for the six studied dams: (a) I-Jurumirim, (b) II-Chavantes, (c) III-Canoas II, (d) IV-Capivara, (e) V-Taquaruçu and (f) VI-Rosana.

An analysis of Figure 2 and Table 2 shows that the water flow increases regularly from reservoir I to reservoir III. A significant increase in the flow is recorded in reservoir IV as a result of the contribution of important tributaries in the middle basin. Reflectance also increases from upstream to downstream, with dams III, IV, V and VI exhibiting higher variability and higher reflectance compared with the upstream dams I and II. The propagation of flow and reflectance peaks throughout the catchment can be easily detected, although the magnitude of each event may vary among the reservoirs. Higher reflectance and discharge values are observed between December 2009 and March 2010 for all reservoirs. During March 2012, high reflectance values are also observed, although the magnitude of the peaks varies among the reservoirs. 
Table 2. Descriptive statistics for the reflectance and water discharge time series recorded between February 2000 and December 2012 for the six studied dams: I-Jurumirim, II-Chavantes, III-Canoas II, IV-Capivara, V-Taquaruçu and VI-Rosana.

\begin{tabular}{ccccccc}
\hline Reservoir & $\begin{array}{c}\text { Reflectance } \\
\text { Mean }\end{array}$ & $\begin{array}{c}\text { Reflectance } \\
\text { Minimum }\end{array}$ & $\begin{array}{c}\text { Reflectance } \\
\text { Maximum }\end{array}$ & $\begin{array}{c}\text { Mean Water } \\
\left.\text { Discharge } \mathbf{( m}^{\mathbf{3}} \mathbf{s}^{-\mathbf{1}}\right)\end{array}$ & $\begin{array}{c}\text { Minimum Water } \\
\text { Discharge }\left(\mathbf{m}^{\mathbf{3}} \mathbf{s}^{-\mathbf{1}}\right)\end{array}$ & $\begin{array}{c}\text { Maximum Water } \\
\left.\mathbf{D i s c h a r g e}^{\left(\mathbf{m}^{\mathbf{3}} \mathbf{s}\right.} \mathbf{- 1}\right)\end{array}$ \\
\hline I-Jurumirim & 0.03 & 0.01 & 0.07 & 236 & 41 & 1135 \\
II-Chavantes & 0.03 & 0.01 & 0.1 & 324 & 85 & 1748 \\
III-Canoas II & 0.06 & 0.03 & 0.12 & 477 & 236 & 7763 \\
IV-Capivara & 0.05 & 0.01 & 0.11 & 1091 & 354 & 8149 \\
V-Taquaruçu & 0.05 & 0.01 & 0.11 & 1137 & 412 & 8202 \\
VI-Rosana & 0.05 & 0.01 & 0.15 & 1288 & & \\
\hline
\end{tabular}

\subsection{Satellite-Based Turbidity Retrieval Model}

Figure 3 presents the correlation between the surface reflectance at red wavelength and the turbidity measurements recorded at the three monitoring stations (intermediate zone reservoir \#I, downstream reservoir \#IV and downstream reservoir \#VI) from June 2000 to December 2012. The mean turbidity value was 8.0 , the median was 6.0 , and the standard deviation was $6.75 \mathrm{NTU}$ (nephelometric turbidity units). The minimum registered value was 1.9 , and the maximum value was 48.0 NTU. For this comparison, reflectance was assessed from the individual eight-day composites, and a virtual station was defined over the station area. When cloud-free images were not available within the seven days before or after the field sampling, the turbidity measurements were removed from the analysis. A regression model was derived using the bootstrap resampling technique that involves resampling of the dataset with repeated replacements to generate an empirical estimate of the sampling distribution [56]. This technique proves particularly useful in cases where the sample data are limited in order to construct confidence intervals for the regression parameters. Because MODIS 250-meter resolution mode offers only two radiometric bands, we chose to use a simple retrieval model. Red wavelength has been shown to be sensitive to low to intermediate suspended sediment concentrations. Consequently, we used the MODIS red band to develop an empirical model for the moderately sediment laden waters of the Paranapanema River. A least squares regression showed that an exponential model, turbidity $=a \cdot e^{b \cdot R s(R e d)}$, where $R_{s}(R e d)$ is the surface reflectance at red wavelength from MOD09/MY09Q1 products, provided the best-fit values, with a $=2.45 \pm 0.42$ (95\% confidence interval) and $b=22.3 \pm 2.8$, which were calculated using 1000 bootstrap samples.

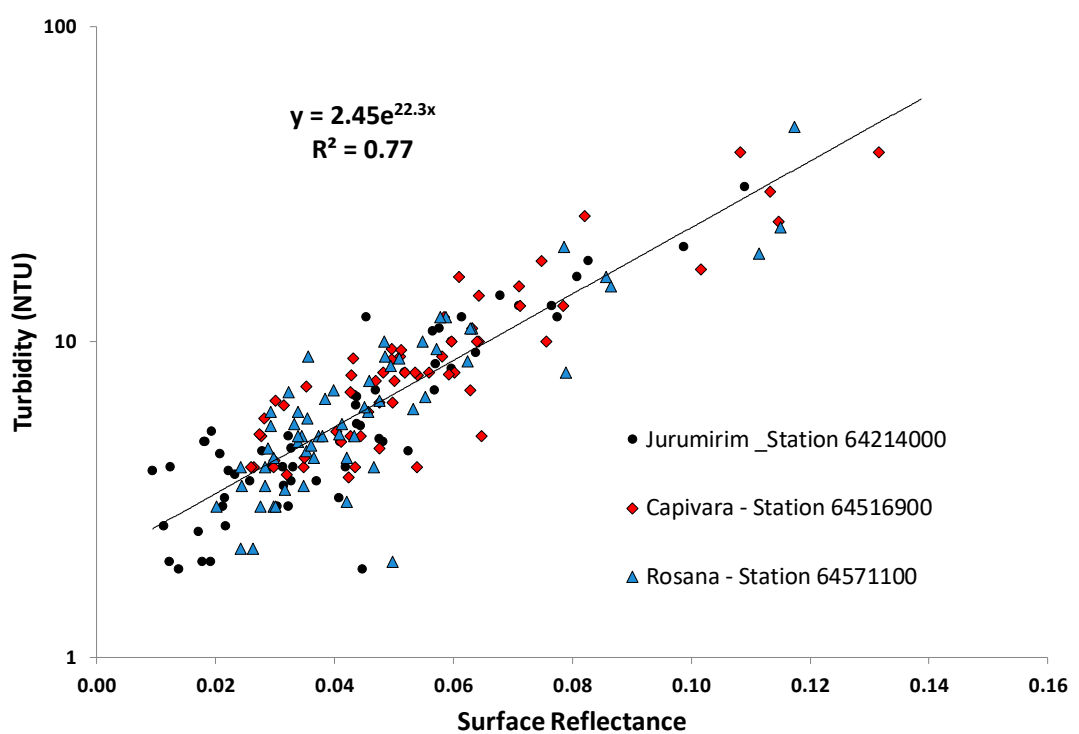

Figure 3. Turbidity as a function of the surface reflectance in the red wavelength range. The points represent consistency between the field turbidity measurements and MODIS data between 2000 and 2012 for three different locations along the Paranapanema River. 
The retrieval model was validated against the independent turbidity dataset for which the turbidity ranged from 1.1 to $87.1 \mathrm{NTU}(\mathrm{N}=138)$. For cloud-free images acquired within the 7 days before or after the field sampling, the satellite-derived turbidity estimates well matched the field estimates, with a root mean square error of $9.5 \mathrm{NTU}(\mathrm{N}=138)$ and a square Pearson correlation factor of 0.75 . Figure 4 shows the model performance over the validation dataset.

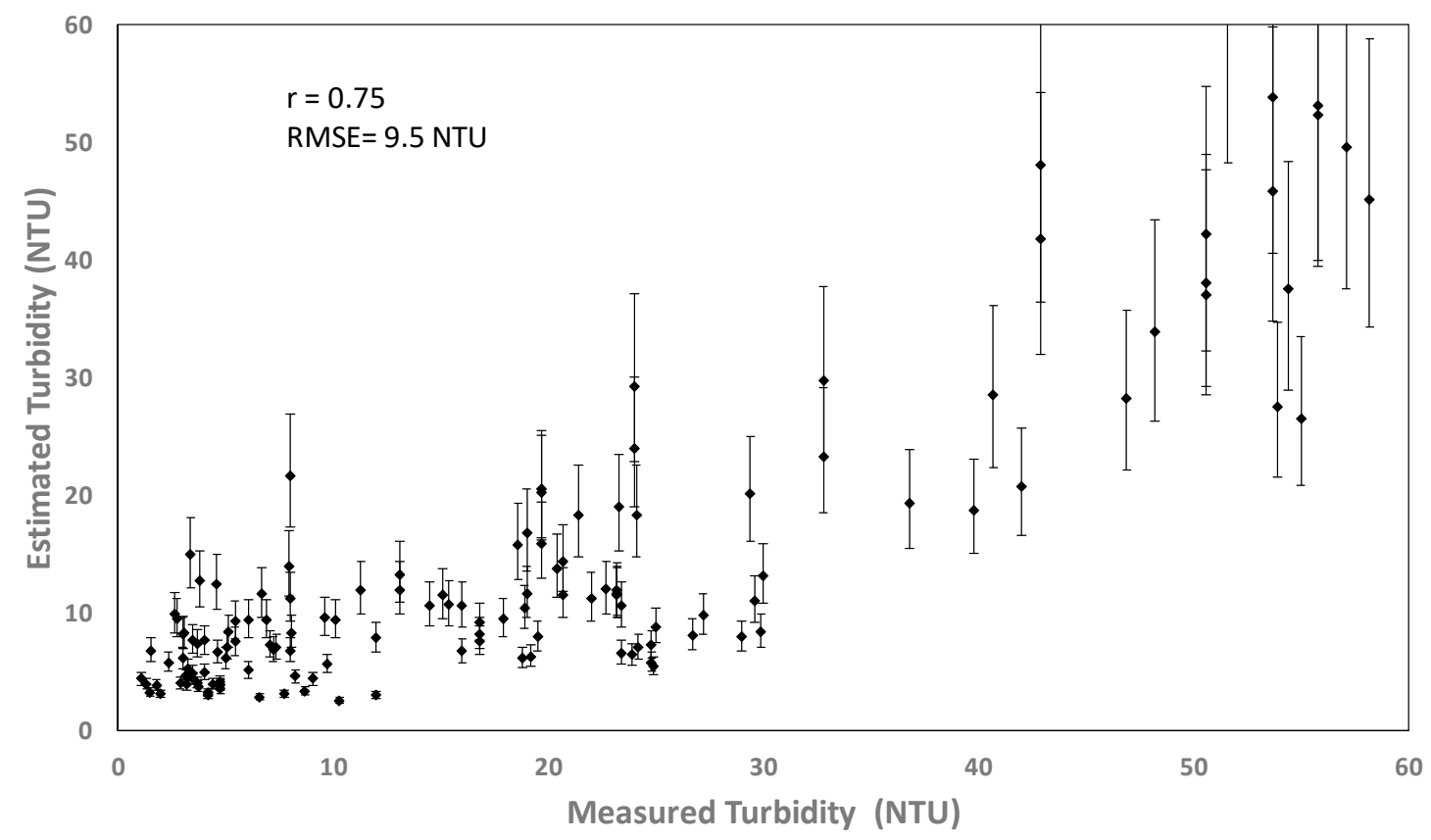

Figure 4. Measured versus estimated turbidity using red reflectance for the validation turbidity data set $(\mathrm{N}=138)$.

\subsection{Analysis of the Seasonal Turbidity Pattern Derived from Modis Images}

Figure 5 shows the variations of remote sensing-retrieved turbidity, which was assessed $50 \mathrm{~km}$ upstream of the Jurumirim Dam, and the daily water inflow into the reservoir between March 2000 and December 2011. The turbidity was assessed using the retrieval model calculated in the previous section. Error bars on the turbidity values were assessed using the $95 \%$ confidence interval estimates based on the retrieval model parameters. The confidence interval on the turbidity estimates encompasses different error sources, including mainly 1) reflectance variability induced by turbidity variability within the virtual station area, especially during the most turbid events and 2) the reflectance/turbidity model accuracy. For some dates, the confidence interval may be higher than the turbidity estimates mainly because turbidity shows significant variation within the virtual station.

Water input was assessed by summing the flows at two stations maintained by the Duke Energy Company, with both stations located upstream of the reservoir tail in the Paranapanema River (Campina do Monte Alegre station) and Apiaí-Guaçu River (Buri station). Although these inputs do not represent the entrance of all water into the reservoir, a good relationship was observed for the lake water turbidity retrieved from satellite data. The maximum turbidity coincided with the rainy season from October to March. Isolated increases in the water discharge during the end of the rainy season from April to July generally did not result in turbidity increases. Overall, the lowest turbidity levels coincided with the low water flow period. Figure S8 shows that the water discharge and satellite-derived turbidity were significantly positively correlated over the twelve-year period, with an adjusted $\mathrm{R}$-squared value of $0.41(\mathrm{~N}=490)$.

Figure S9 presents another comparison of water input versus turbidity such as in Figure 5 but for reservoir \#IV and over a shorter time span of 3.5 years in order to better retrieve individual events. The water turbidity was determined in the reservoir tail zone $63 \mathrm{~km}$ upstream of the dam. 
The water flow was estimated by summing the nearest upstream reservoir outflow (reservoir \#III) and the discharge from two local tributaries, the Laranjinha River at Santa Terezinha gauge and the Cinzas River at Andirá gauge. Despite the distances from these water inputs, a coupled fluctuation generally occurred between both variables. Again, good correlations were observed between the high flow events and remote sensing-retrieved turbidity levels, especially at the beginning of the rainy period.

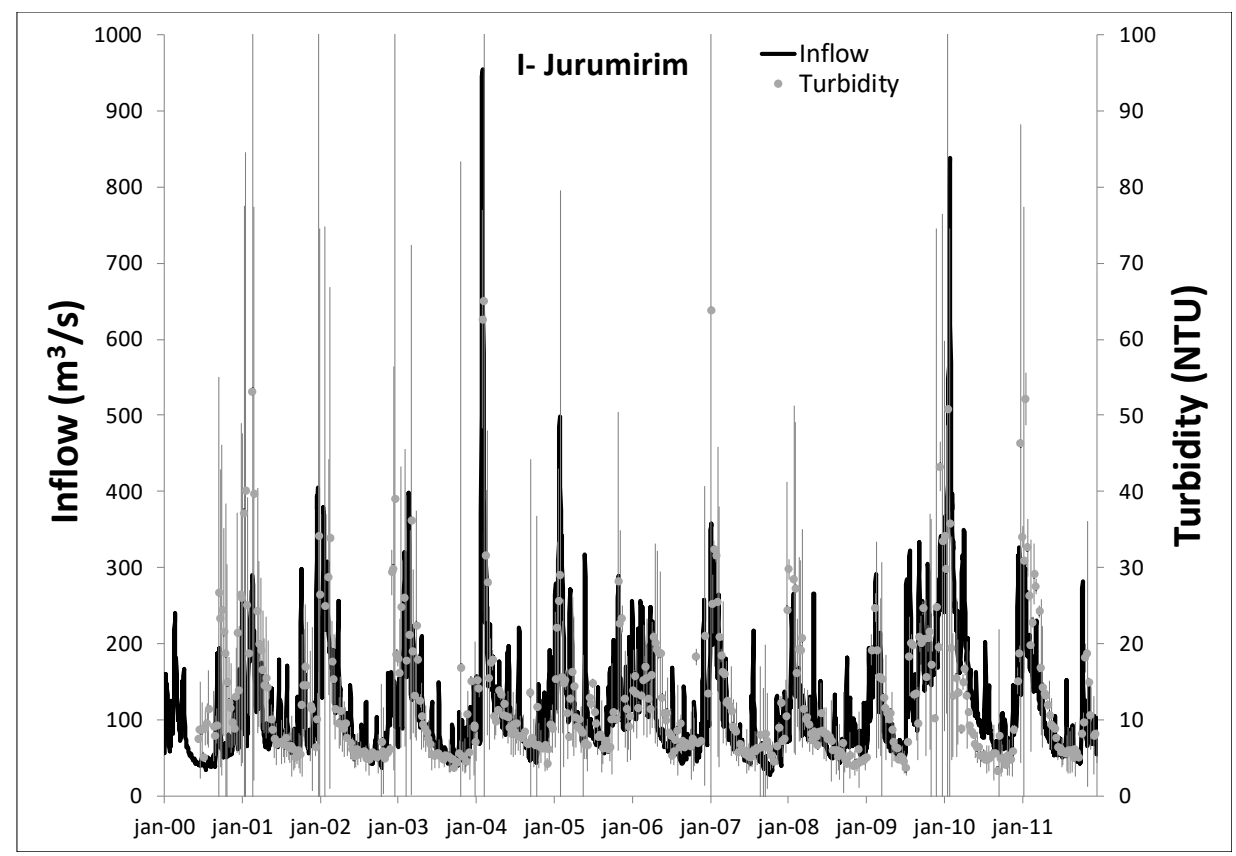

Figure 5. Variation of river discharge and remote sensing-retrieved turbidity in the tail zone of reservoir \#I from 2000 to 2011.

\subsection{Retrieval of the Spatiotemporal Sedimentation Patterns in the Jurumirim Reservoir}

To apply remote sensing data to the study of reservoir dynamics, we performed an analysis of the spatial and temporal variability of water turbidity retrieved by the satellite for reservoir \#I. Ten virtual stations based on approximately 6-km-long masks were created from the upstream to downstream (Figure S7), and the monthly turbidity estimations were averaged over the entire period of study, from June 2000 to March 2013.

Figure 6 presents the monthly averaged remote sensing-based turbidity from January to December for six virtual stations (out of ten virtual stations created) distributed along the main axis of the Jurumirim reservoir. This latter reservoir was selected because it allows detail in the monitoring and analysis of the longitudinal changes in sedimentary processes, as it is one of the largest reservoirs along the Paranapanema River main stream. The monthly averaged water inputs are also displayed on the second vertical axis. A large spatial gradient is observed for the turbidity, especially during the rainy season from October to March. As expected, the turbidity decreased sharply as the water flowed into the lacustrine region of the reservoir; in addition, a sharp gradient was located in the upstream portion of the lake, and the variations in turbidity were reduced in the last $22 \mathrm{~km}$. The temporal variation of the turbidity was obviously dependent on the water inflow from the upstream reservoir. Even a minor variation in the water input during the rainy season was reflected in the temporal fluctuation of the turbidity, such as during the small oscillation in water entrance from October to November and from November to December. The rate of decrease of turbidity from the Jurumirim reservoir tail (J10) downstream to the dam reservoir (J1) varies throughout the hydrological cycle. Three periods can be discriminated: from December to March, at the time of the largest inflow to the reservoir, there is an average turbidity decrease of $74 \%$. From June to November, the period of lowest inflow to the 
reservoir, the average turbidity decrease is $42 \%$. Finally, for intermediary flows, from April to May, the average turbidity decrease is $59 \%$.

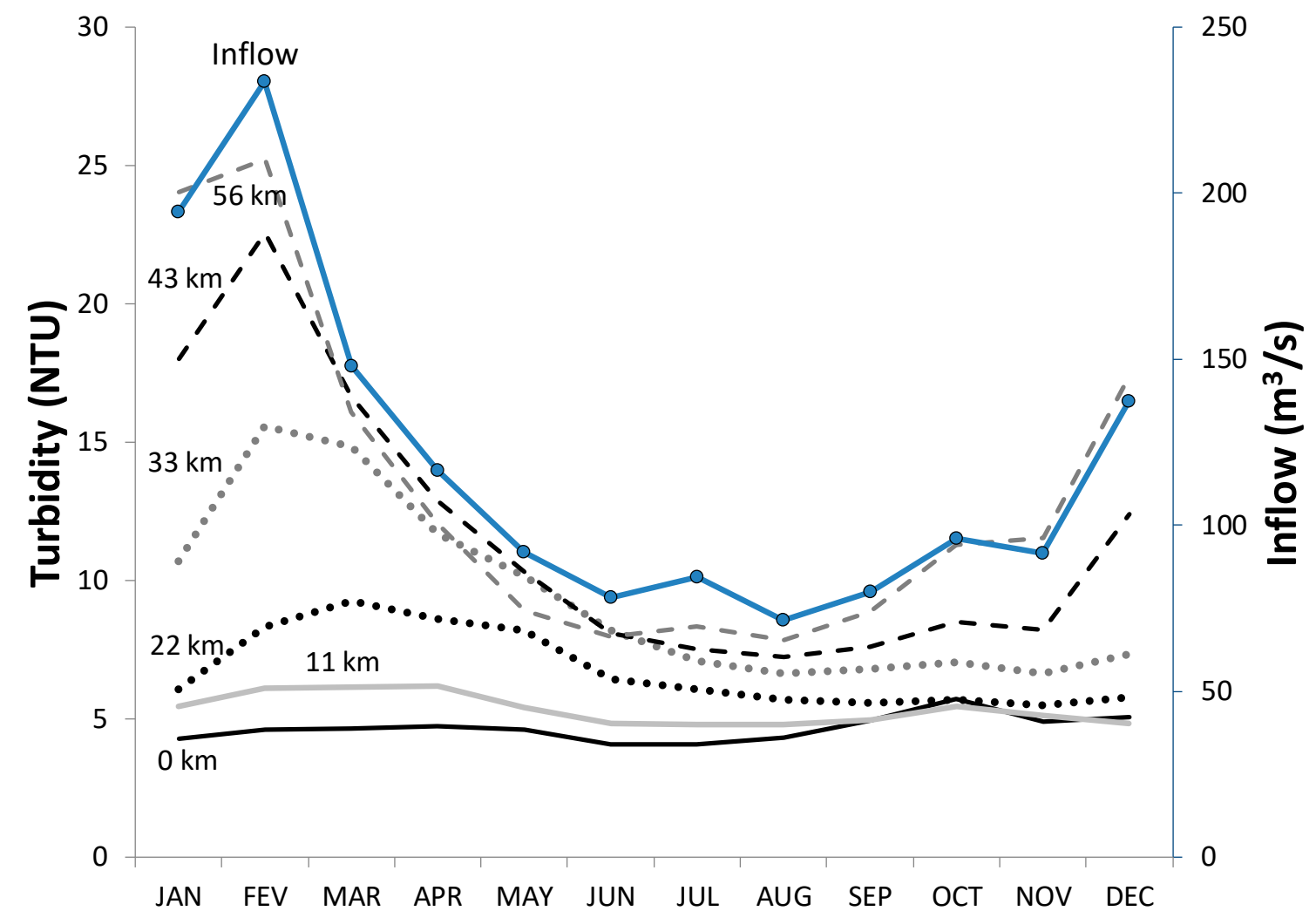

Figure 6. Water input and monthly averaged remote sensing-derived turbidity retrieved from 2000 to 2013 for six different virtual stations of reservoir \#I. The distance of each virtual station to the reservoir impoundment is expressed in kilometers.

To demonstrate the longitudinal sedimentation gradient within the reservoir, Figure 7 shows the turbidity as a function of the distance from the dam to the beginning of the impoundment, which is 56 $\mathrm{km}$ upstream. A clear longitudinal gradient can be observed, and the decreased turbidity was much less pronounced in the last $22 \mathrm{~km}$ of the reservoir. This result is consistent with general knowledge of reservoir hydrodynamics, which predicts a decrease in water velocity and an increase in water column depth as a function of distance within the reservoir. The strong turbidity gradient was greatly influenced by the large area of the reservoir $\left(449 \mathrm{~km}^{2}\right)$ and long water residence time of 340 days. A similar turbidity pattern was retrieved from previous field measurements [41] for variations in suspended matter in this same reservoir as well as a significant decrease in nutrient concentration and an increase in transparency in the vicinity of the dam zone in relation to the upstream measurements. Field measurements of the sedimentation rates also demonstrated increased values in the upstream compartments [57].

\subsection{Dam Operation Demonstrated by Remote Sensing Analyses}

The Paranapanema River is characterized by a succession of large-storage reservoirs and smaller run-of-river reservoirs. Although the large impoundments significantly alter the natural hydrodynamics of the river, the run-of-river projects usually preserve the natural flows. In this context, we analyzed how the different impoundment types interfere with the sedimentation pattern, which is similar to what was presented in the previous section for dam \#1. Figure 8 shows the monthly turbidity averages for each reservoir, and the dam and upstream zones were both considered. The calculated mean, minimum and maximum turbidity values are summarized in Table 3. 


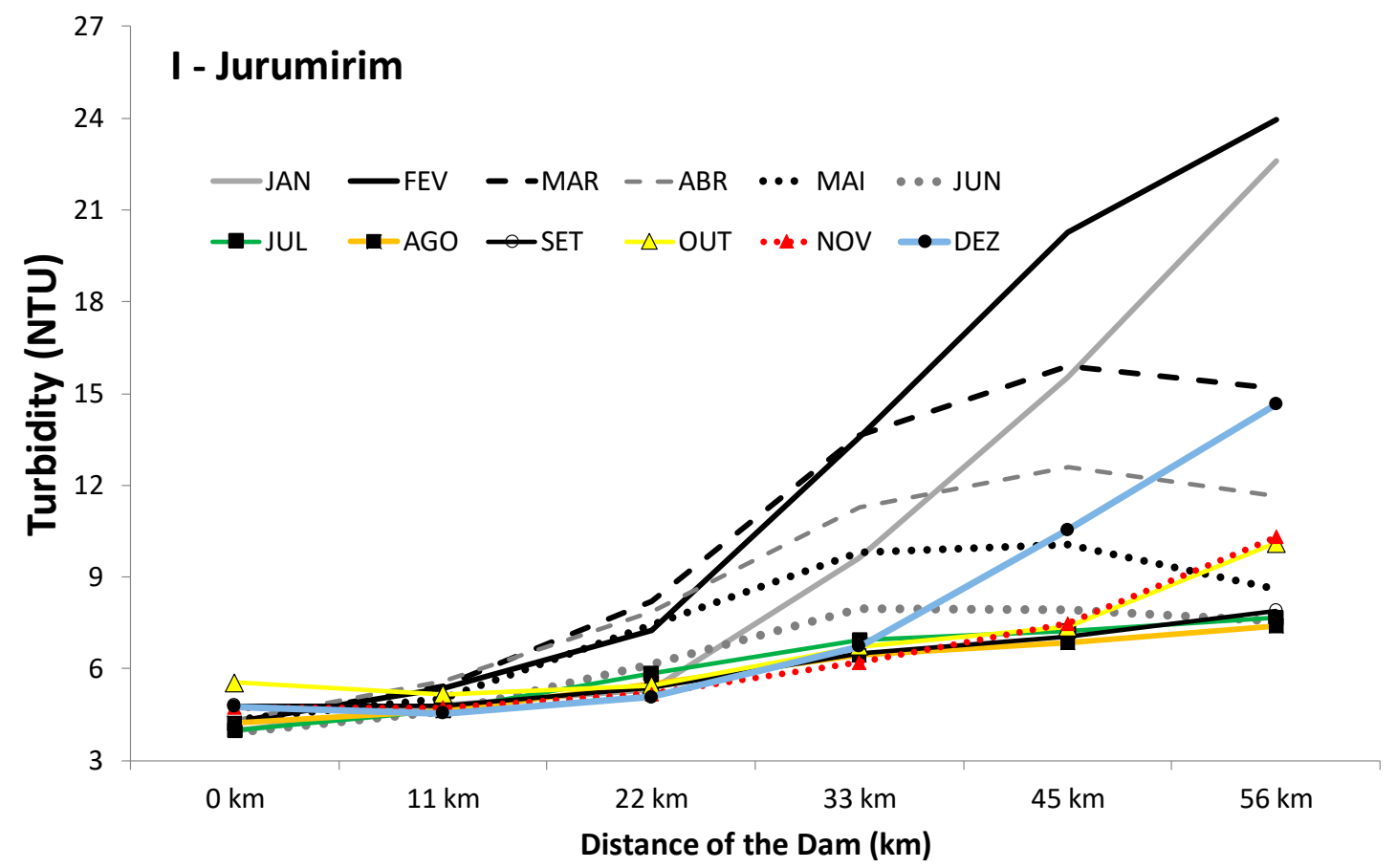

Figure 7. Monthly longitudinal variation of remote sensing-based turbidity in reservoir \#1 (mean values for 2000-2013).

Table 3. The mean, minimum and maximum turbidity calculated for all of the reservoirs.

\begin{tabular}{cccccc}
\hline \multirow{2}{*}{ Reservoirs } & \multirow{2}{*}{ Position } & \multicolumn{4}{c}{ Turbidity Calculated (NTU) } \\
\cline { 3 - 6 } & & Mean & Mean Jan/Feb & Minimum & Maximum \\
\hline \multirow{2}{*}{ I-Jurumirim } & Dam & 4.7 & 4.4 & 2.9 & 12.5 \\
& Upstream & 12.4 & 23.1 & 4.1 & 43.6 \\
\hline \multirow{2}{*}{ II-Chavantes } & Dam & 5.1 & 6.4 & 3.0 & 20.7 \\
& Upstream & 8.8 & 11.2 & 2.9 & 41.2 \\
\hline \multirow{2}{*}{ III-Canoas II } & Dam & 10.0 & 15.3 & 4.4 & 37.3 \\
& Upstream & 10.0 & 14.8 & 4.6 & 27.0 \\
\hline \multirow{2}{*}{ IV-Capivara } & Dam & 8.4 & 10.0 & 3.1 & 31.3 \\
& Upstream & 13.3 & 21.9 & 3.3 & 67.6 \\
\hline \multirow{2}{*}{ V-Taquaruçu } & Dam & 10.0 & 12.1 & 4.1 & 41.6 \\
& Upstream & 11.5 & 16.8 & 4.2 & 76.4 \\
\hline \multirow{2}{*}{ VI-Rosana } & Dam & 9.5 & 12.2 & 2.8 & 70.4 \\
& Upstream & 11.2 & 14.8 & 3.8 & 51.2 \\
\hline
\end{tabular}

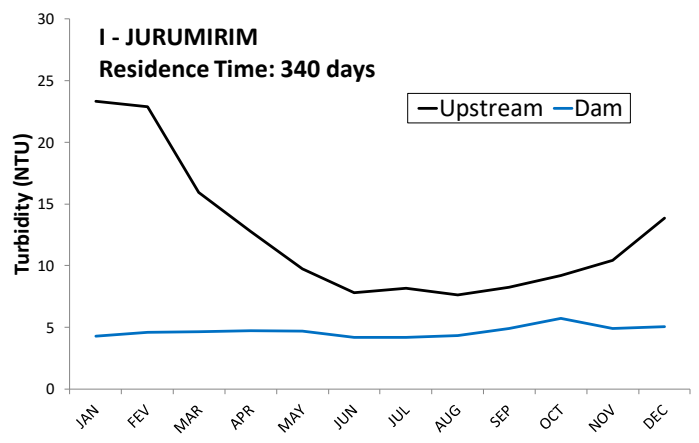

(a)

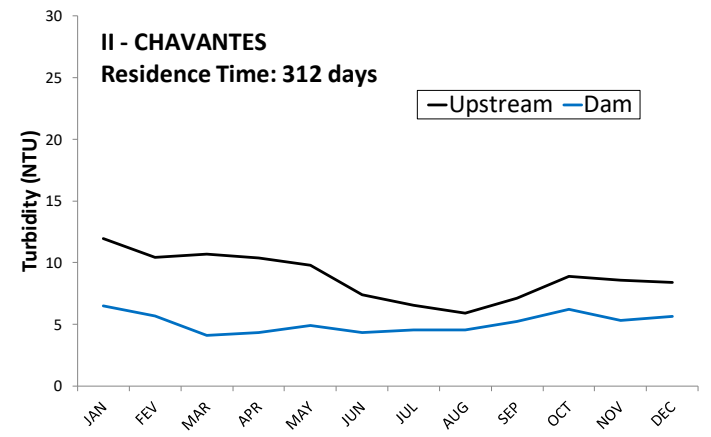

(b)

Figure 8. Cont. 


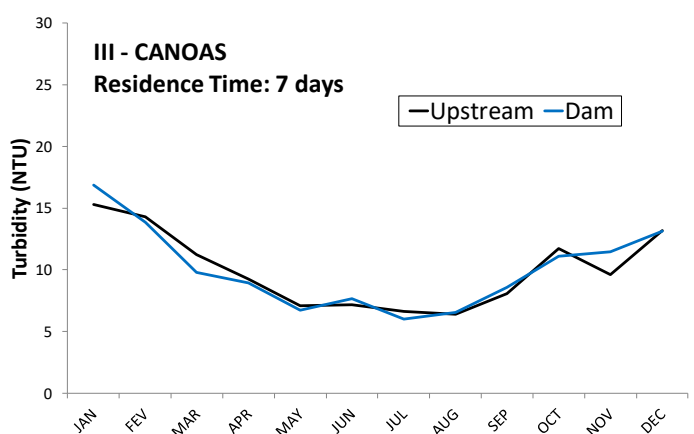

(c)

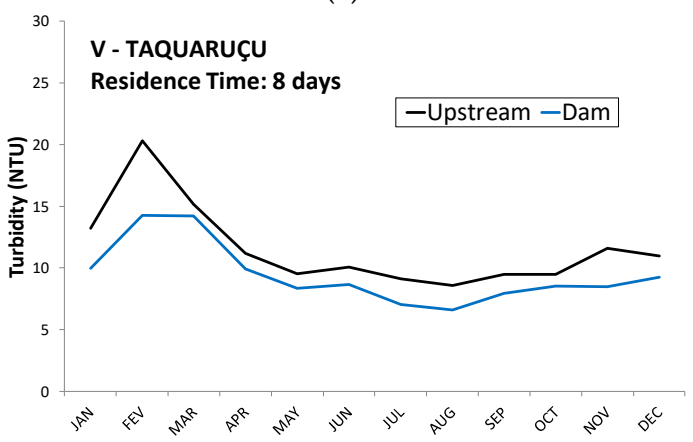

(e)

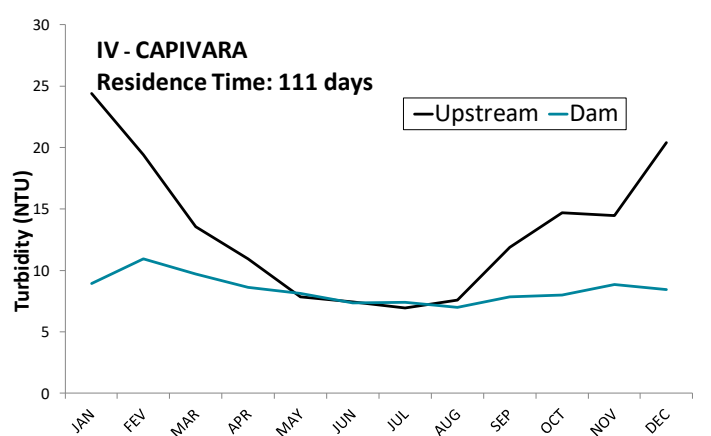

(d)

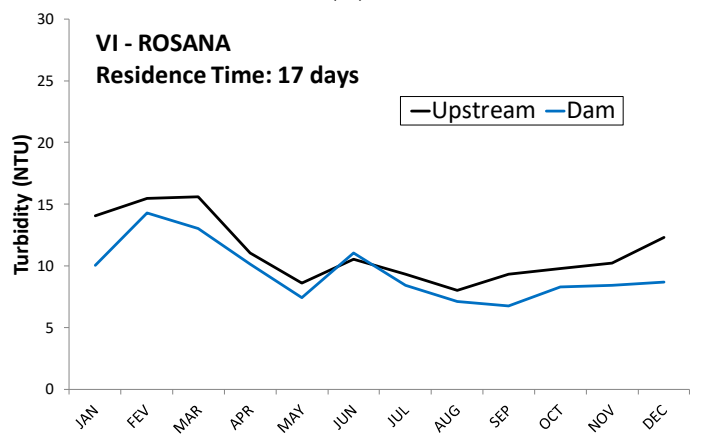

(f)

Figure 8. Monthly longitudinal remote sensing-based turbidity variation (2000-2013) in the hydropower reservoirs of the Paranapanema River.

For most of the reservoirs, the upstream turbidity values are higher than those calculated for the dam zone. A greater reduction in turbidity is observed for reservoir \#I ( $-7.7 \mathrm{NTU})$, reservoir \#II $(-3.7 \mathrm{NTU})$ and reservoir \#IV $(-4.9 \mathrm{NTU})$ compared with the mean interannual turbidity. The turbidity reduction is much more limited for reservoir \#II $(0.0 \mathrm{NTU})$, reservoir \#V $(-1.5 \mathrm{NTU})$ and reservoir \#VI $(-1.7 \mathrm{NTU})$.

There is a general and non-uniform increasing trend in turbidity along the river basin according to the dam zone data, with mean interannual values ranging from 4.7 (reservoir \#1) to 9.5 NTU (reservoir \#VI), although both are run-of the river dams.

In Figure 8, two sedimentation patterns can be clearly distinguished among the different reservoirs. The first pattern presents large turbidity variations within the reservoir and corresponds to reservoirs \#I, \#II and \#IV. These three reservoirs are marked by long water residence times (Table 1) exceeding 100 days. In this configuration, a high sedimentation rate may be expected because of strong hydraulic dam control. The second pattern presents low water turbidity variations across the reservoir main axis and corresponds to reservoirs \#III, \#V and \#VI. These impoundments are characterized by a low water residence time between 7 and 17 days (Table 1), and they can be classified as run-of-river dams that exhibit lower sedimentation processes and river flow control. Although the size of reservoir \#VI is between that of the major (\#I and \#II) and smaller (\#III and \#VI) impoundments, this reservoir shows a pattern that justifies its classification in the run-of-river reservoir class. Indeed, this reservoir shows a limited lateral extension and does not exhibit the dendritic spatial pattern typical of the large impoundments. Furthermore, this reservoir is located in the last stretch of the river basin and receives large water inflows of $1288 \mathrm{~m}^{3} \cdot \mathrm{s}^{-1}$ on average.

\subsection{Quantification of Reservoir Sediment Trap Efficiency}

Reservoir trap efficiency is the percentage of incoming sediment deposited in a reservoir during the hydrological cycle. It is a function of detention storage time, character of the sediment, nature of the inflow, and other factors [48]. We analyzed if the spatial and seasonal pattern in the remote 
sensing derived turbidity can be quantified and provide robust estimates in relation to conventional methods predicting the sedimentation/trap efficiency in the reservoirs. We computed (i) the empirical trap efficiency for fine sediment $\mathrm{TE}_{\mathrm{FS}}$ from Equation (1) using hydrological data for each year from

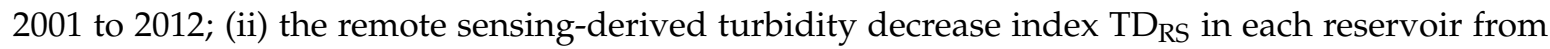
Equation (2) and from the reflectance time series and (iii) the remote sensing-derived $T_{R S}$ from Equation (3) obtained from a, b, c, d parameters determined from the regression and for each year. Figure S10 shows the $\mathrm{TE}_{\mathrm{FS}}$ and the $\mathrm{TD}_{\mathrm{RS}}$ for each reservoir and averaged over the 2001-2012 period. Both $\mathrm{TD}_{\mathrm{RS}}$ and $\mathrm{TE}_{\mathrm{FS}}$ show similar behavior $\left(\mathrm{r}^{2}=0.83\right)$ however systematic underestimations occur in relation to the theoretical behavior of the TEFS. Figure 9 compares $\mathrm{TE}_{\mathrm{FS}}$ and $\mathrm{TE} \mathrm{E}_{\mathrm{RS}}$, expressed as a percentage, for the six reservoirs as a function water residence time calculated for each year. The fitted parameters for the $\mathrm{TE}_{\mathrm{RS}}$ model were $[0.6438 ; 24.4792 ;-61.5512 ; 43.8501]$ for $[\mathrm{a}, \mathrm{b}, \mathrm{c}, \mathrm{d}]$ respectively. $\mathrm{TE}_{\mathrm{FS}}$ and $\mathrm{TE}_{\mathrm{RS}}$ agree well for the overall estimate $\left(\mathrm{r}^{2}=0.90, \mathrm{~N}=6\right)$ as well as for the annual estimates $\left(r^{2}=0.66, N=72, \mathrm{RMSE}=16.9 \%\right)$, with a rapid increase for the smallest residence times and a plateau for the largest residence times of approximately 100 days.

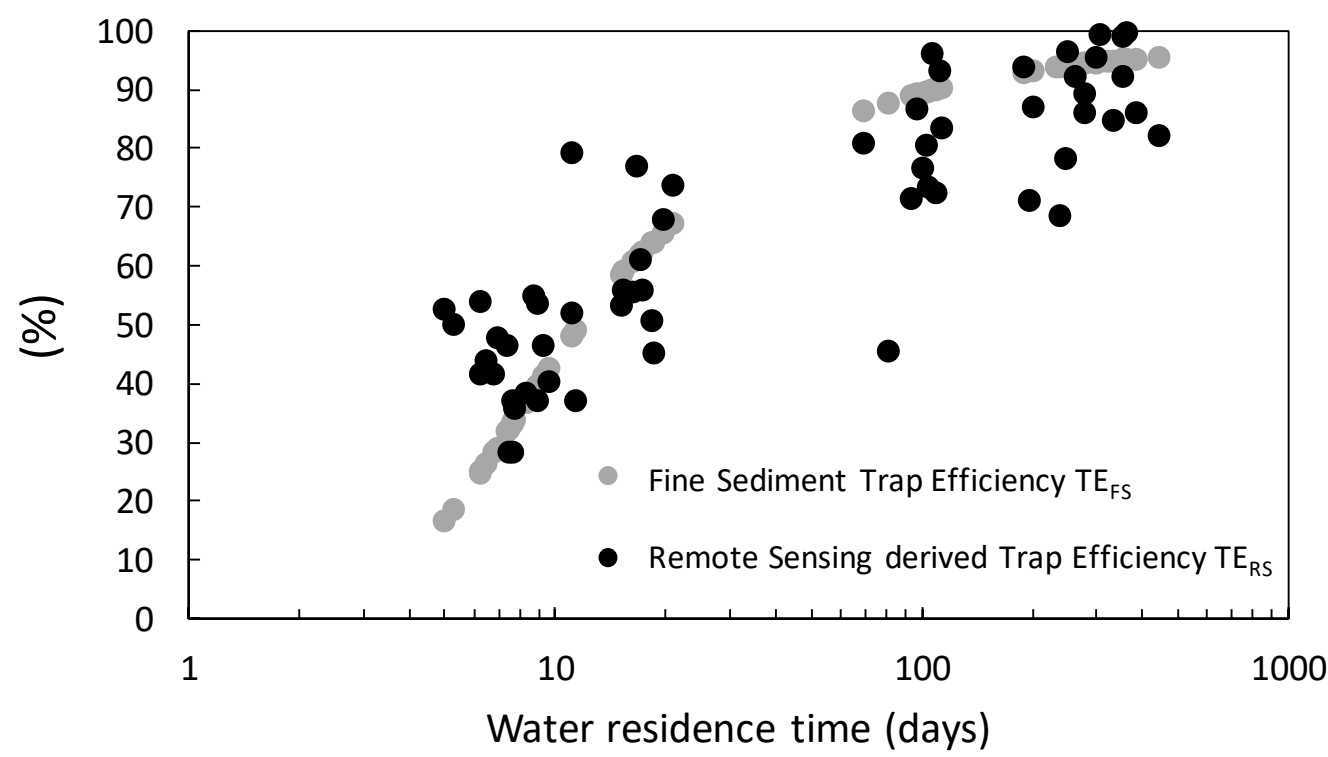

Figure 9. Comparison between the sediment trapping efficiency for fine suspended sediment $\mathrm{TE}_{\mathrm{FS}}$ (grey circles) assessed using Equation (1) and the remote sensing-derived trapping efficiency $\mathrm{TE}_{\mathrm{RS}}$ (black circles), calculated using Equation (3), for the 6 reservoirs studied and for all the years from 2001 to 2012.

\section{Discussion}

Our results demonstrate the ability of MODIS images to monitor fine turbidity variations on a long-term basis in reservoirs, even for low levels of turbidity of approximately 2 NTU. In particular, the remote sensing-derived estimates and field datasets (Figure 3) present satisfactory consistency considering the differences in terms of sampling areas. Compared with the conventional quarterly sampling practice, satellite data can be used to monitor sedimentary processes with a much higher frequency and can detect peak sedimentary fluxes associated with rapid flood events. Additionally, MODIS data can be used to monitor water surface turbidity at both the reservoir and catchment scale, thus demonstrating their suitability as a tool for river water monitoring and management. We showed that the satellite images can provide consistent estimates of the sedimentation when compared with conventional trap efficiency methods based uniquely on hydrological data (e.g., reservoir capacity and inflow time series).

An high phytoplankton abundance (higher than $30 \mu \mathrm{g} \cdot \mathrm{L}^{-1}$ ) can significantly reduce the accuracy of SPM retrieval from reflectance in turbid inland waters characterized by heterogeneous SPM and 
Chl-a concentrations [19]. However, the chlorophyll values in the aquatic systems of the Paranapanema basin are consistently low, generally around or lower than $3 \mu \mathrm{g} \cdot \mathrm{L}^{-1}$. This pattern has been observed for the entire reservoir cascade [42], including both storage and run-of-river reservoirs [58,59]. Even in lateral lagoons where phytoplankton development is favored, the chlorophyll values remain between 2 and $3 \mu \mathrm{g} \cdot \mathrm{L}^{-1}$ [60]. Under these conditions, we assume that phytoplankton does not significantly alter the relationship between SPM and reflectance.

The influence of the lake bottom on satellite-retrieved reflectance may be a concern for shallow water systems. The penetration depth is defined as the maximum depth from which an optical sensor receives a detectable signal from a water body [61]. Practically, it is defined using the rate of decrease of the downwelling irradiance, which is known to decrease in an approximately exponential manner with depth. The penetration depth z90, i.e., the depth above which 90 percent of the upwelling irradiance originates, has been defined by [62] as z90 =1/Kd, where $\mathrm{Kd}$ is the downwelling diffuse attenuation coefficient. Furthermore, [14] states that Kd and the Secchi depth (SD) are closely related, with $\mathrm{Kd}=1.44 / \mathrm{SD}$. Consequently, $\mathrm{z} 90=\mathrm{SD} / 1.44$. Based on eight sampling campaigns conducted along the whole river stretch, a mean SD of $2.29 \mathrm{~m}$ was calculated [42], from which a mean z90 of $1.6 \mathrm{~m}$ was derived. The penetration depth is consequently much lower than the mean water depth, which varies from $6 \mathrm{~m}$ to $21 \mathrm{~m}$ depending on the reservoir. Furthermore, the lake depth exhibits very restricted variation ( $\mathrm{a}$ few tenths of a $\mathrm{cm}$ ) because the river flow is regulated for hydropower generation; therefore, we conclude that the lake bottom may only alter the satellite-derived reflectance for the pixels located along the shores that are automatically removed during MODIS image post-processing with MOD3R as they present a signature mixed with that of the shores.

The remote sensing data indicated a global increase in water turbidity at the river surface from upstream (reservoir \#I) to downstream (reservoir \#VI). This result may appear inconsistent with the expected increase in sedimentation processes along the reservoir cascade. However, a longitudinal increase in turbidity, chlorophyll and nutrients was observed in the water column and bottom sediments of the Paranapanema River, which has been previously reported. [37,63] indicated that mass transference processes can surpass sedimentation processes in the catchment because of the increased agricultural activities/soil uses, especially in the middle and middle/lower stretches of the basin, which cause an increase in suspended sediment discharge in the local drainage network downstream of reservoirs \#I and \#II. The case of reservoir \#III is interesting; it is located below two major impoundments and a decrease in water turbidity would be expected in this latter reservoir. Nevertheless, the remote sensing data indicated that there is an increase from 8.8 to 10 NTU, which is likely caused by the entrance of the Pardo River into this reservoir. The Pardo River is a left-bank medium-sized tributary of the Paranapanema River that drains areas recognized as highly sensitive to erosion processes and intensive cultivation [64].

The Jurumirim Reservoir has been shown to be compartmentalized in riverine, transitional and lacustrine functional zones. A strong sedimentation rate in the upstream segment and a mean sedimentation rate of $4.71 \mathrm{mg} \cdot \mathrm{cm}^{-2}$. day ${ }^{-1}$ was recorded during two field campaigns [57]. The same authors showed a rapid reduction in the sedimentation rate in the riverine and most upstream transition zones of approximately $66 \%$. Near the reservoir dam, a mean sedimentation rate of $0.66 \mathrm{mg} \cdot \mathrm{cm}^{-2} \cdot \mathrm{day}^{-1}$ was measured [57]. In the lacustrine zone near the dam, the water transparency was considerably high during most of the year, even in the rainy summers [65]. Secchi disk readings reached $5.16 \mathrm{~m}$, and only occasionally were lower than $2.0 \mathrm{~m}$. These patterns are consistent with the remote sensing-derived observations that show a stable turbidity zone near the dam and an abrupt decrease of water turbidity in the transition zone during the rainy season (Figure 7).

In this article, we proposed a methodology to analyze the spatial and temporal variation of turbidity across reservoirs from space in order to quantify sedimentation processes. The water body is partitioned in consecutive virtual stations representing small buffer zones in order to cover the riverine, transitional and lacustrine functional zones. The reflectance time series are averaged over each buffer zone to retrieve the seasonal variation of the turbidity and as a function of distance within 
the reservoir. The rate of decrease of the turbidity assessed with remote sensing images $\mathrm{TD}_{\mathrm{RS}}$ has been quantified with an index (Equation (2)) calculating the relative variation of the turbidity from the most upstream to the most downstream virtual station in the reservoir. The TEFS and the TD $\mathrm{RS}_{\mathrm{F}}$ are well correlated over a large range of reservoir type/water residence times (from seven days to 340 days) but the remote sensing-derived estimates show systematic underestimation.

Because solar light does not penetrate beyond a depth of several meters in the water column, satellite images exclusively record the water quality at the lake surface and are not necessarily representative of all water column properties. Stratification processes within the reservoir that depend on environmental conditions (wind, incoming solar radiation, water and air temperatures) limit vertical water fluxes within the reservoir and may control the depth at which the river water plunges into the reservoir transition region [66]. Consequently, the turbidity decrease retrieved from satellite data do not capture all of the sediment fluxes because a portion of the river suspended sediment may enter through interflow (e.g., beneath the light penetration depth) according to the environmental conditions or through bottom flow for coarser material (e.g., sand). Because the satellites cannot see all the input sediment discharge from the monitoring of the water surface, it likely explains the systematic underestimation of the $\mathrm{TD}_{\mathrm{RS}}$ index in relation to conventional trap efficiency modeling.

Although the $\mathrm{TD}_{\mathrm{RS}}$ index underestimates the $\mathrm{TE}_{\mathrm{FS}}$, both estimates are well correlated confirming that the satellite-based turbidity provide representative assessment of the sedimentation processes within reservoirs for fine sediment. Indeed, sediment transport in river systems in turbulent flows predict a relatively constant vertical distribution of the fine-grained size sediment fraction in the water column [52], meaning that surface concentration is generally well correlated with the column integrated mean suspended sediment concentration. It is worthwhile noting that Equation (1) represents a simplified model of the sediment transport in reservoir that does not consider additional sediment inputs from local tributaries entering in different parts of a reservoir. Local inflows and sediment inputs may experience lower residence times compared with the water entering through the river mainstream, and this inconsistency may reduce the effective reservoir trap efficiency in comparison to the modeled one. The $\mathrm{TE}_{\mathrm{RS}}$ index was defined to correct the $\mathrm{TD}_{\mathrm{RS}}$ bias and was built using the same empirical equation that [53] used to model the relationship between water residence time and trap efficiency observed by [49]. Using regression analysis, $\mathrm{TE}_{\mathrm{RS}}$ matched well the $\mathrm{TE}_{\mathrm{FS}}$ and made possible to retrieve the sedimentation interannual variability that is driven by multiple factors that are hardly represented by empirical models uniquely based on hydrological data. In particular, $\mathrm{TD}_{\mathrm{RS}}$ and $\mathrm{TE}_{\mathrm{RS}}$ variability is probably linked with additional factors such as lateral inflows from ungauged rivers, varying particle size distribution during flooding events from the upstream inflows or flushing operations from upstream reservoirs. These additional factors are of great interest for reservoir sustainable management and further work is needed to fully assess the dependency of the TE $E_{R S}$ to hydrological and sedimentological characteristics of the river and reservoirs.

Medium resolution sensors offering near-daily global coverage such as MODIS, Sentinel-3 or VIIRS appear very well adapted to follow most important sediment discharge events that usually occur during period marked by strong cloud coverage. The period over which most of the sediment discharge is transported in a river system is usually very short. [67], for example, assessed that 40 to $80 \%$ of annual suspended sediment fluxes occurred within $2 \%$ of the time in four different catchments. The ability to capture, very frequently, the river and reservoirs for turbidity assessment is consequently a major constrain for the selection of an adequate spaceborne sensor.

However, the coarse spatial resolution of medium resolution sensors such as MODIS images (at best $250 \mathrm{~m}$ ) makes it difficult to monitor the most upstream sections of the reservoirs, which are generally less than $100 \mathrm{~m}$ wide. Consequently, the most upstream virtual station usually does not match the exact region where the river waters enter the reservoir lake (see Figure S1 for reservoir \#I), possibly causing an underestimation of the sediment inflow to the reservoir. The use of higher-resolution satellite data that provide complete images of the riverine region of a reservoir would overcome this limitation. However, the revisiting frequency of the sensors offering spatial resolutions 
between $10 \mathrm{~m}$ and $30 \mathrm{~m}$ (e.g., Landsat-8, Sentinel-2, etc.) is at best a few days and is likely inadequate to catch the water bodies with sufficient frequency during the strongest sediment discharge events.

The synoptic coverage offered by satellite data, in particular with medium resolution sensors, brings an unprecedented knowledge on fine sediment transport in reservoirs in comparison to conventional sedimentary surveys. These conventional measurements are realized through annual or multiannual bathymetric measurements or quarterly to monthly water sampling in most reservoirs across the world. Consequently, the availability of remote sensing images from near-daily to monthly resolution, taking into consideration only the cloud-free images, improves the assessment of the sediment input and distribution within reservoirs during the most important sediment discharge events that are hardly caught by field measurements. The spatial coverage offered by the satellite data is of particular interest for the large reservoirs that are not surveyed with the necessary frequency because of the time-consuming and very costly field conventional measurements. Finally, the use of remote sensing-based methods for sediment trap efficiency assessment would support a global assessment of reservoir sedimentation in major reservoirs, representing thousands of lakes across the world [9].

\section{Conclusions}

MODIS satellite data delivered a robust turbidity assessment over a 700-km long river transect, identifying extreme sediment discharge events occurring from daily to annual scales. By analyzing the turbidity pattern variability in each reservoir, we retrieved the sedimentation pattern at the water surface, allowing us to discriminate run-of-river reservoirs with shorter water residence time from larger reservoirs operating for flow control and exhibiting higher residence times.

The reduction in turbidity assessed from space presented a good relationship with conventional sediment trapping efficiency calculations, demonstrating the potential of this technology for operational sedimentation monitoring in reservoirs across large catchments.

Supplementary Materials: The following are available online at http:/ /www.mdpi.com/2072-4292/11/3/314/s1, Figure S1. Above: MODIS virtual station locations showing the two masks representing the most upstream and downstream areas considered for the Jurumirim reservoir. The distance between two virtual stations is of $50 \mathrm{~km}$. Below: location of the MODIS 250-m pixel centers (yellow points) within each mask. MOD3R retrieval procedure used in this study eliminates automatically mixed pixels based on their spectra values at red and near-infrared channels.S1: title, Figure S2. Above: MODIS virtual station locations showing the two masks representing the most upstream and downstream areas considered for the Chavantes reservoir. The distance between two virtual stations is of $33 \mathrm{~km}$. Below: location of the MODIS 250-m pixel centers (yellow points) within each mask. MOD3R retrieval procedure used in this study eliminates automatically mixed pixels based on their spectra values at red and near-infrared channels, Figure S3. Above: MODIS virtual station locations showing the two masks representing the most upstream and downstream areas considered for the Canoas II reservoir. The distance between two virtual stations is of $13 \mathrm{~km}$. Below: location of the MODIS 250-m pixel centers (yellow points) within each mask. MOD3R retrieval procedure used in this study eliminates automatically mixed pixels based on their spectra values at red and near-infrared channels, Figure S4. Above: MODIS virtual station locations showing the two masks representing the most upstream and downstream areas considered for the Capivara reservoir. The distance between two virtual stations is of $50 \mathrm{~km}$. Below: location of the MODIS 250-m pixel centers (yellow points) within each mask. MOD3R retrieval procedure used in this study eliminates automatically mixed pixels based on their spectra values at red and near-infrared channels, Figure S5. Above: MODIS virtual station locations showing the two masks representing the most upstream and downstream areas considered for the Taquaruçu reservoir. The distance between two virtual stations is of $12 \mathrm{~km}$. Below: location of the MODIS 250-m pixel centers (yellow points) within each mask. MOD3R retrieval procedure used in this study eliminates automatically mixed pixels based on their spectra values at red and near-infrared channels, Figure S6. Above: MODIS virtual station locations showing the two masks representing the most upstream and downstream areas considered for the Rosana reservoir. The distance between two virtual stations is of $20 \mathrm{~km}$. Below: location of the MODIS 250-m pixel centers (yellow points) within each mask. MOD3R retrieval procedure used in this study eliminates automatically mixed pixels based on their spectra values at red and near-infrared channels, Figure S7. Virtual stations created along reservoir I (Jurumirim Reservoir), which were used to process the MODIS eight-day composite image time series, Figure S8. Variations in the river discharge and remote sensing-retrieved turbidity in the tail zone of reservoir \#I from 2000 to 2011, Figure S9. Variation in the river inflow and satellite-derived turbidity for the Capivara Reservoir, Figure S10. Comparison between the sediment trapping efficiency TEFS assessed using Equation (1) and the remote sensing-retrieved turbidity decrease TDRS, calculated using Equation (2), for the 6 
reservoirs studied and for the period of observation. The error bars stand for the standard deviation of all years from 2001 to 2012.

Author Contributions: Conceptualization, R.d.C.C. and J.-M.M.; Methodology, R.d.C.C. and J.-M.M.; Software, R.d.C.C., J.-M.M. and G.C.; Validation, R.d.C.C., J.-M.M., M.A.P and M.N.; Formal Analysis, R.d.C.C. and J.-M.M.; Investigation, R.d.C.C., J.-M.M., M.N. and R.V.; Data Curation, R.d.C.C. and J.-M.M.; Writing-Original Draft Preparation, R.d.C.C. and J.-M.M.; Writing-Review \& Editing, R.d.C.C., J.-M.M., M.N., R.H., R.V., M.A.P. and W.L.

Funding: This research received no external funding.

Acknowledgments: This work has been supported by the cooperation project "Spatial Hydrological monitoring in large catchments-MEG HIBAM", executed by the Brazilian Water Agency (ANA) and the Institut de Recherche pour Le Développement (IRD), within the framework of the Brazilian Cooperation Agency. Our thanks are extended to São Paulo State Environmental Agency (CETESB), to UNESP Botucatu (Instituto de Biociências) and Duke Energy for providing data and reports on the turbidity and hydrology of the Paranapanema River catchment. The data used in this paper will be made available by contacting the corresponding author.

Conflicts of Interest: The authors declare no conflict of interest.

\section{References}

1. Brandt, S.A. Classification of geomorphological effects downstream of dams. Catena 2000, 40, 375-401. [CrossRef]

2. Kempe, S. Impact of Aswan High Dam on Water Chemistry of the Nile. Transport of Carbon and Minerals in Major World Rivers, Pt. 2. Mitt Geol.-Palaeont. Inst. Univ. Hamburg. SCOPE/UNEP Sonderbd. 1983, 55, 401-423.

3. Humborg, C.; Ittekkot, V.; Cociasu, A.; Bodungen, B.V. Effect of Danube River dam on Black Sea biogeochemistry and ecosystem structure. Nature 1997, 386, 385-388. [CrossRef]

4. World Commission on Dams. Dams and Development: A New Framework for Decision-Making: The Report of the World Commission on Dams. Earthscan Publications Ltd., 2000; p. 404. Available online: https:/ / www.internationalrivers.org/sites / default/files/attached-files/world_commission_on_ dams_final_report.pdf (accessed on 24 July 2018).

5. Vörösmarty, C.J.; Meybeck, M.; Fekete, B.; Sharma, K.; Green, P.; Syvitski, J.P. Anthropogenic sediment retention: Major global impact from registered river impoundments. Glob. Planet. Chang. 2003, 39, 169-190. [CrossRef]

6. Syvitski, J.P.; Vörösmarty, C.J.; Kettner, A.J.; Green, P. Impact of humans on the flux of terrestrial sediment to the global coastal ocean. Science 2005, 308, 376-380. [CrossRef] [PubMed]

7. Moran, E.F.; Lopez, M.C.; Moore, N.; Müller, N.; Hyndman, D.W. Sustainable hydropower in the 21st century. Proc. Natl. Acad. Sci. USA 2018, 115, 11891-11898. [CrossRef] [PubMed]

8. Palmieri, A.; Shah, F.; Dinar, A. Economics of reservoir sedimentation and sustainable management of dams. J. Environ. Manag. 2001, 61, 149-163. [CrossRef]

9. Morris, G.; Fan, J. Reservoir Sedimentation Handbook; McGraw-Hill Book Co.: New York, NY, USA, 1998.

10. Bishwakarma, M.B.; Støle, H. Real-time sediment monitoring in hydropower plants. J. Hydraul. Res. 2008, 46, 282-288. [CrossRef]

11. Kelman, J.; Pereira, M.V.F.; Neto, T.A.A.; Sales, P.D.H.; Vieira, A.D.M. Hidreletricidade. In Águas Doces no Brasil: Capital Ecológico, uso e Conservação, 3nd ed.; Rebouças, A.C., Braga, B., Tundisi, J.G., Eds.; Escrituras: São Paulo, Brazil, 2006; pp. 507-543. ISBN 8586303410.

12. Stevaux, J.C.; Martins, D.P.; Meurer, M. Changes in a large regulated tropical river: The Paraná River downstream from the Porto Primavera Dam, Brazil. Geomorphology 2009, 113, 230-238. [CrossRef]

13. Walling, D.E. The Impact of Global Change on Erosion and Sediment Transport by Rivers: Current Progress and Future Challenges; Unesco-IHP: Paris, France, 2009; p. 26.

14. Kirk, J.T. Light and Photosynthesis in Aquatic Ecosystems; Cambridge University Press: Cambridge, UK, 2011; p. 662. ISBN 9780521151757.

15. Babin, M.; Morel, A.; Fournier-Sicre, V.; Fell, F.; Stramski, D. Light scattering properties of marine particles in coastal and open ocean waters as related to the particle mass concentration. Limnol. Oceanogr. 2003, 48, 843-859. [CrossRef] 
16. Martinez, J.M.; Espinoza-Villar, R.; Armijos, E.; Silva Moreira, L. The optical properties of river and floodplain waters in the Amazon River Basin: Implications for satellite-based measurements of suspended particulate matter. J. Geophys. Res. Earth Surf. 2015, 120, 1274-1287. [CrossRef]

17. Neukermans, G.; Loisel, H.; Mériaux, X.; Astoreca, R.; McKee, D. In situ variability of mass-specific beam attenuation and backscattering of marine particles with respect to particle size, density, and composition. Limnol. Oceanogr. 2012, 57, 124-144. [CrossRef]

18. Snyder, W.A.; Arnone, R.A.; Davis, C.O.; Goode, W.; Gould, R.W.; Ladner, S.; Weidemann, A. Optical scattering and backscattering by organic and inorganic particulates in US coastal waters. Appl. Opt. 2008, 47, 666-677. [CrossRef]

19. Song, K.S.; Li, L.; Tedesco, L.; Duan, H.T.; Li, L.; Du, J. Remote Quantification of Total Suspended Matter through Empirical Approaches for Inland Waters. J. Environ. Inf. 2014, 23, 23-36. [CrossRef]

20. Kumar, A.; Equeenuddin, S.M.; Mishra, D.R.; Acharya, B.C. Remote monitoring of sediment dynamics in a coastal lagoon: Long-term spatio-temporal variability of suspended sediment in Chilika Estuarine. Coast. Shelf Sci. 2016, 170, 155-172. [CrossRef]

21. Hu, C.; Chen, Z.; Clayton, T.D.; Swarzenski, P.; Brock, J.C.; Muller-Karger, F.E. Assessment of estuarine water-quality indicators using MODIS medium-resolution bands: Initial results from Tampa Bay, FL. Remote Sens. Environ. 2004, 93, 423-441. [CrossRef]

22. Wang, H.; Hladik, C.M.; Huang, W.; Milla, K.; Edmiston, L.; Harwell, M.A.; Schalles, J.F. Detecting the spatial and temporal variability of chlorophyll-a concentration and total suspended solids in Apalachicola Bay, Florida using MODIS imagery. Int. J. Remote Sens. 2010, 31, 439-453. [CrossRef]

23. Montanher, O.C.; Novo, E.M.; Barbosa, C.C.; Rennó, C.D.; Silva, T.S. Empirical models for estimating the suspended sediment concentration in Amazonian white water rivers using Landsat 5/TM. Int. J. Appl. Earth Obs. Geoinf. 2014, 29, 67-77. [CrossRef]

24. Park, E.; Latrubesse, E.M. Modeling suspended sediment distribution patterns of the Amazon River using MODIS data. Remote Sens. Environ. 2014, 147, 232-242. [CrossRef]

25. Zhu, W.; Yu, Q.; Tian, Y.Q.; Becker, B.L.; Zheng, T.; Carrick, H.J. An assessment of remote sensing algorithms for colored dissolved organic matter in complex freshwater environments. Remote Sens. Environ. 2014, 140, 766-778. [CrossRef]

26. Robert, E.; Grippa, M.; Kergoat, L.; Pinet, S.; Gal, L.; Cochonneau, G.; Martinez, J.M. Monitoring water turbidity and surface suspended sediment concentration of the Bagre Reservoir (Burkina Faso) using MODIS and field reflectance data. Int. J. Appl. Earth Obs. Geoinf. 2016, 52, 243-251. [CrossRef]

27. Long, C.M.; Pavelsky, T.M. Remote sensing of suspended sediment concentration and hydrologic connectivity in a complex wetland environment. Remote Sens. Environ. 2013, 129, 197-209. [CrossRef]

28. Chen, S.; Han, L.; Chen, X.; Li, D.; Sun, L.; Li, Y. Estimating wide range Total Suspended Solids concentrations from MODIS 250-m imageries: An improved method. ISPRS J. Photogram. Remote Sens. 2015, 99, 58-69. [CrossRef]

29. Wang, J.-J.; Lu, X. Estimation of suspended sediment concentrations using Terra MODIS: An example from the Lower Yangtze River, China. Sci. Total Environ. 2010, 408, 1131-1138. [CrossRef] [PubMed]

30. Santos, A.L.M.R.; Martinez, J.M.; Filizola, N.P., Jr.; Armijos, E.; Alves, L.G.S. Purus River suspended sediment variability and contributions to the Amazon River from satellite data (2000-2015). Comptes Rendus Geosci. 2017, 350, 13-19. [CrossRef]

31. Martinez, J.M.; Guyot, J.-L.; Filizola, N.; Sondag, F. Increase in suspended sediment discharge of the Amazon River assessed by monitoring network and satellite data. Catena 2009, 79, 257-264. [CrossRef]

32. Villar, R.E.; Martinez, J.M.; Guyot, J.L.; Fraizy, P.; Armijos, E.; Crave, A.; Bazán, H.; Vauchel, P.; Lavado, W. The integration of field measurements and satellite observations to determine river solid loads in poorly monitored basins. J. Hydrol. 2012, 444, 221-228. [CrossRef]

33. Mangiarotti, S.; Martinez, J.M.; Bonnet, M.P.; Buarque, D.C.; Filizola, N.; Mazzega, P. Discharge and suspended sediment flux estimated along the mainstream of the Amazon and the Madeira Rivers (from in situ and MODIS Satellite Data). J. Appl. Earth Obs. Geoinf. 2013, 21, 341-355. [CrossRef]

34. Latrubesse, E.M.; Arima, E.Y.; Dunne, T.; Park, E.; Baker, V.R.; d'Horta, F.M.; Ribas, C.C. Damming the rivers of the Amazon basin. Nature 2017, 546, 363-369. [CrossRef] 
35. Villar, R.E.; Martinez, J.M.; Le Texier, M.; Guyot, J.L.; Fraizy, P.; Meneses, P.R.; Oliveira, E. A study of sediment transport in the Madeira River, Brazil, using MODIS remote-sensing images. J. South Am. Earth Sci. 2013, 44, 45-54. [CrossRef]

36. Lima, J.E.F.W.; Lopes, W.T.A.; Silva, E.M. Diagnóstico do Fluxo de Sedimentos em Suspensão na Bacia do Rio Paranapanema. In Proceedings of the XVI Simpósio Brasileiro de Recursos Hídricos (SBRH), João Pessoa, Brazil, 20-25 November 2005; Available online: https:/ / bit.ly/2Trin1t (accessed on 24 July 2018).

37. Nogueira, J.A.; Vianna, N.C.; Britto, Y.C. Reservatórios em cascata e os efeitos na limnologia e organização das comunidades bióticas (fitoplâncton, zooplâncton e zoobentos): Um estudo de caso no rio Paranapanema (SP/PR). In Ecologia de Reservatórios: Estrutura, Função e Aspectos Sociais; Henry, R., Ed.; FUNDIBIO: Botucatu, Brazil, 2006; p. 800. ISBN 9788590112914.

38. Agência Nacional de Águas. A Navegação Interior e sua Interface com o Setor de Recursos Hídricos no Brasil e Aproveitamento do Potencial Hidráulico para Geração de Energia no Brasil; Cadernos de Recursos Hídricos; Agência Nacional de Águas: Brasília, Brazil, 2012; Volume 3, p. 170.

39. Ferrareze, M.; Nogueira, M.G. Phytoplankton assemblages and limnological characteristics in lotic systems of the Paranapanema Basin (Southeast Brazil). Acta Limnol. Bras. 2006, 18, 389-405.

40. Nogueira, G.M.; Naliato, D.A.O.; Perbiche-Neves, G. Limnology of Two Contrasting Hydroelectric Reservoirs (Storage and Run-of-River) in Southeast Brazil; INTECH Open Access Publisher: London, UK, 2012; Available online: https: / / bit.ly/2Ry0zzQ (accessed on 25 July 2018).

41. Nogueira, G.M.; Henry, R.; Maricatto, F.E. Spatial and temporal heterogeneity in the Jurumirim reservoir, São Paulo, Brazil. Lakes Reserv. Res. Manag. 1999, 4, 107-120. [CrossRef]

42. Nogueira, M.G.; Ferrareze, M.; Moreira, M.; Gouvêa, R. Phytoplankton assemblages in a reservoir cascade of a large tropical-subtropical river (SE, Brazil). Braz. J. Biol. 2010, 70, 781-793. [CrossRef]

43. Nogueira, M.G.; Oliveira, P.C.R.; de Britto, Y.T. Zooplankton assemblages (Copepoda and Cladocera) in a cascade of reservoirs of a large tropical river (SE Brazil). Limnetica 2008, 27, 151-169.

44. Agência Nacional de Águas. A Navegação Interior. Caderno de Recursos Hidricos, 3; Agência Nacional de Águas: Brasília, Brazil, 2007; 170p.

45. APHA. Standard Methods for the Examination of Water and Waste Water, 22th ed.; American Public Health Association: Washington, DC, USA, 2012; pp. 2-15. ISBN 9780875530130.

46. Rymszewicz, A.; O'Sullivan, J.J.; Bruen, M.; Turner, J.N.; Lawler, D.M.; Conroy, E.; Kelly-Quinn, M. Measurement differences between turbidity instruments, and their implications for suspended sediment concentration and load calculations: A sensor inter-comparison study. J. Environ. Manag. 2017, 199, 99-108. [CrossRef] [PubMed]

47. Pinto, C.E.T.; Menezes, P.H.B.J.; Martinez, J.M.; Roig, H.L.; Villar, R.A.E. Use of MODIS images to monitor the sediment inflow into the Três Marias reservoir. R. Bras. Eng. Agríc. Ambiental. 2014, 18, 507-516. [CrossRef]

48. Verstraeten, G.; Poesen, J. Estimating trap efficiency of small reservoirs and ponds: Methods and implications for the assessment of sediment yield. Prog. Phys. Geogr. 2000, 24, 219-251. [CrossRef]

49. Brune, G.M. Trap efficiency of reservoirs. Eos Trans. Am. Geophys. Union 1953, 34, 407-418. [CrossRef]

50. Churchill, M.A. Discussion of paper by L. C. Gottschalk "Analyses and use of reservoir sedimentation data". In Federal Inter-Agency Sedimentation Conference Proceedings; USGS: Denver, CO, USA, 1948; pp. 139-140.

51. Heinemann, H.G. A new sediment trap efficiency curve for small reservoirs. Water Resour. Bull. 1981, 17, 825-830. [CrossRef]

52. Rouse, H. Experiments on the Mechanics of Sediment Suspension. In Fifth International Congress for Applied Mechanics; Wiley: Cambridge, UK, 1938.

53. Gill, M.A. Sedimentation and useful life of reservoirs. J. Hydrol. 1979, 44, 89-95. [CrossRef]

54. Lewis, S.E.; Bainbridge, Z.T.; Kuhnert, P.M.; Sherman, B.S.; Henderson, B.; Dougall, C.; Brodie, J.E. Calculating sediment trapping efficiencies for reservoirs in tropical settings: A case study from the Burdekin Falls Dam, NE Australia. Water Resour. Res. 2013, 49, 1017-1029. [CrossRef]

55. Fylstra, D.; Lasdon, L.; Watson, J.; Waren, A. Design and use of the Microsoft Excel Solver. Interfaces 1998, 28, 29-55. [CrossRef]

56. Wehrens, R.; Putter, H.; Buydens, L.M.C. The bootstrap: A tutorial. Chemom. Intell. Lab. Syst. 1999, 54, 35-52. [CrossRef]

57. Henry, R.; Maricato, F. Sedimentation rates of tripton in Jurumirim Reservoir (São Paulo, Brazil). Limnologica 1996, 5-25. Available online: http:/ /hdl.handle.net/11449/64734 (accessed on 24 July 2018). 
58. Naliato, D.A.O.; Nogueira, M.G.; Perbiche-Neves, G. Discharge pulses of hydroelectric dams and their effects in the downstream limnological conditions: A case study in a large tropical river (SE Brazil). Lakes Reserv. Res. Manag. 2009, 14, 301-314. [CrossRef]

59. Ferrareze, M.; Casatti, L.; Nogueira, M.G. Spatial heterogeneity affecting fish fauna in cascade reservoirs of the Upper Paraná Basin, Brazil. Hydrobiologia 2014, 738, 97-109. [CrossRef]

60. Ferrareze, M.; Nogueira, M.G. Phytoplankton assemblages in lateral lagoons of a large tropical reservoir. Braz. J. B. 2013, 73, 163-171. [CrossRef]

61. Uncles, R.J.; Mitchell, S.B. (Eds.) Estuarine and Coastal Hydrography and Sediment Transport; Cambridge University Press: Cambridge, UK, 2017; ISBN 9781139644426.

62. Gordon, H.R.; McCluney, W.R. Estimation of the depth of sunlight penetration in the sea for remote sensing. Appl. Opt. 1975, 14, 413-416. [CrossRef]

63. Jorcin, A.; Nogueira, M.G. Temporal and spatial patterns based on sediment and sediment-water interface characteristics along a cascade of reservoirs (Paranapanema River, south-east Brazil). Lakes Reserv. Res. Manag. 2005, 10, 1-12. [CrossRef]

64. Departamento de Águas e Energia Elétrica. Plano Estadual de Recursos Hídricos 2004-2007; Departamento de Águas e Energia Elétrica (DNAE): São Paulo, Brazil, 2007; p. 92. Available online: http:/ /www.daee.sp.gov. br/acervoepesquisa/perh/perh2204_2207/perh20042007.htm (accessed on 12 October 2018).

65. Sartori, L.; Nogueira, M.; Henry, R.; Moretto, E. Zooplankton fluctuations in Jurumirim Reservoir (São Paulo, Brazil): A three-year study. Braz. J. Biol. 2009, 69, 1-18. [CrossRef]

66. Jorgensen, S.E.; Loffler, H.; Rast, W.; Straskraba, M. Lake and Reservoir Management, 54; Elsevier: Amsterdam, The Netherlands, 2005; p. 325. ISBN 0444516786.

67. Mano, V.; Némery, J.; Belleudy, P.; Poirel, A. Assessment of suspended sediment transport in four alpine watersheds (France): Influence of the climatic regime. Hydrol. Process. 2009, 14, 777-792. [CrossRef]

(C) 2019 by the authors. Licensee MDPI, Basel, Switzerland. This article is an open access article distributed under the terms and conditions of the Creative Commons Attribution (CC BY) license (http:/ / creativecommons.org/licenses/by/4.0/). 